\title{
Functional characterization of cinnamyl alcohol dehydrogenase and caffeic acid O-methyltransferase in Brachypodium distachyon
}

\author{
Gina M Trabucco ${ }^{1,2}$, Dominick A Matos ${ }^{1,2}$, Scott J Lee ${ }^{1,3}$, Aaron J Saathoff ${ }^{4}$, Henry D Priest ${ }^{5}$, Todd C Mockler ${ }^{5}$, \\ Gautam Sarath $^{4}$ and Samuel P Hazen ${ }^{1 *}$
}

\begin{abstract}
Background: Lignin is a significant barrier in the conversion of plant biomass to bioethanol. Cinnamyl alcohol dehydrogenase (CAD) and caffeic acid O-methyltransferase (COMT) catalyze key steps in the pathway of lignin monomer biosynthesis. Brown midrib mutants in Zea mays and Sorghum bicolor with impaired CAD or COMT activity have attracted considerable agronomic interest for their altered lignin composition and improved digestibility. Here, we identified and functionally characterized candidate genes encoding CAD and COMT enzymes in the grass model species Brachypodium distachyon with the aim of improving crops for efficient biofuel production.

Results: We developed transgenic plants overexpressing artificial microRNA designed to silence BdCAD1 or BdCOMT4. Both transgenes caused altered flowering time and increased stem count and weight. Downregulation of BdCAD1 caused a leaf brown midrib phenotype, the first time this phenotype has been observed in a $C_{3}$ plant. While acetyl bromide soluble lignin measurements were equivalent in BdCAD1 downregulated and control plants, histochemical staining and thioacidolysis indicated a decrease in lignin syringyl units and reduced syringyl/guaiacyl ratio in the transgenic plants. BdCOMT4 downregulated plants exhibited a reduction in total lignin content and decreased Maule staining of syringyl units in stem. Ethanol yield by microbial fermentation was enhanced in amiR-cad1-8 plants.
\end{abstract}

Conclusion: These results have elucidated two key genes in the lignin biosynthetic pathway in B. distachyon that, when perturbed, may result in greater stem biomass yield and bioconversion efficiency.

\section{Background}

Plant biomass offers a sustainable, low-carbon-emitting source of biofuel feedstock to potentially alleviate both environmental and economic disadvantages of fossil fuel usage [1]. Fossil fuel combustion has resulted in elevated atmospheric $\mathrm{CO}_{2}$ levels that continue to rise, threatening air quality, wildlife habitat, and human health $[2,3]$. A viable, cost-effective alternative is to replace and/or blend gasoline and diesel fuels with biofuel. The efficiency of existing approaches to generating biofuels can be improved through research into plant feedstock attributes, namely biomass yield and recalcitrance to conversion [4].

\footnotetext{
* Correspondence: hazen@bio.umass.edu

'Biology Department, University of Massachusetts 221 Morrill Science Center III, Amherst, MA 01003, USA

Full list of author information is available at the end of the article
}

Plant cell walls are mostly comprised of cellulose, hemicellulose, and lignin. The composition and interaction among these three constituents largely dictate the amenability of a plant feedstock for conversion to simple sugars and then to biofuels. Cellulose and hemicellulose are important raw materials, for they are an abundant source of monomeric sugars that can be hydrolyzed by enzymes and fermented by microbes, while lignin cannot [5]. Due to the recalcitrance of plant cell walls, a strong acid, heat, or other chemical pretreatment is required to first break up cell wall fibers and access the polysaccharides for enzyme treatment. Lignin in particular can impede the pretreatment process by adhering to the hydrolytic enzymes used to saccharify cellulose and other polysaccharides, affecting their ability to work efficiently. Additionally, some lignin degradation products can inhibit subsequent fermentation steps by releasing aromatic compounds that inhibit enzymes used for converting sugars to ethanol [6]. Saccharification of

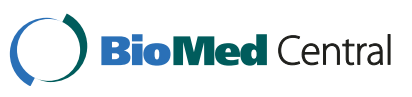


Medicago sativa expressing antisense transcripts designed to silence lignin biosynthesis genes showed an inverse relationship between lignin content and sugar yield, revealing that lignin is indeed a significant obstacle to obtaining high yields of cell wall sugars [7]. Consequently, there has been strong interest in the engineering of bioenergy crops, namely grasses, that are more amenable to feedstock conversion, notably by the manipulation of lignin biosynthesis, in order to improve efficiency of the pretreatment process and obtain maximum fuel yield [8].

Lignin is a complex phenolic polymer, and despite its recalcitrant properties, it is important in providing structural support, hydrophobicity, and protection against pathogens [9]. It is comprised of $p$-hydroxyphenyl $(\mathrm{H})$, guaiacyl (G), and syringyl (S) units derived from the monolignol precursors $p$-coumaryl, coniferyl, and sinapyl alcohols, respectively. A series of ten enzymes is involved in the phenylpropanoid pathway for monolignol biosynthesis [9]. The eudicot Arabidopsis thaliana has served as a valuable tool to understand lignin biosynthesis [9]. However, there are major plant cell wall structural differences between eudicots and grasses including the type and abundance of lignocellulosic components, pectins, and proteins and the linkages between them [10,11].

Cinnamyl-alcohol dehydrogenase (CAD) functions in one of the final steps of monolignol biosynthesis that catalyzes the reduction of cinnamyl aldehyde to cinnamyl alcohol prior to polymerization into the lignin polymer. The highly conserved Rossmann fold NAD(P)H/NAD(P)+ binding domain found in $\mathrm{CAD}$ monolignol-synthesizing proteins indicates the use of NADPH as a cofactor in the reduction reaction [12]. $C A D$ tends to exist in multi-gene families with one gene being primarily responsible for lignin biosynthesis. The effect of $C A D$ downregulation has been studied using a transgenic approach in several eudicot species including Nicotiana tabacum [13-16], M. sativa [17], Populus sp. [18-20] and Eucalyptus camaldulensis [21]. Reports of lignin modification by downregulation of $C A D$ in grasses are limited to Panicum virgatum [22,23], Zea mays [24], and Festuca arundinacea [25]. In general, the transgenic downregulation of $C A D$ does not affect total lignin content; instead, the inhibition of monolignol biosynthesis leads to changes in lignin composition, such as incorporation of accumulated aldehyde precursors or novel units into the lignin polymer, changes that make biomass more digestible [26].

Caffeic acid $O$-methyltransferase (COMT) is an $O$ methyltransferase that tends to be broad in substrate affinity and can potentially act in various branches of the phenylpropanoid pathway. The highly conserved Sadenosyl methionine (SAM) binding domain in COMT proteins indicates the use of SAM as the methyl group donor to the hydroxyl group of a methyl acceptor molecule [27]. COMT is involved in the methylation of caffeic acid to ferulic acid, which is then hydroxylated at position five by ferulate-5-hydroxylase. The subsequent methylation by COMT at this position yields sinapic acid. Similarly, COMT catalyzes the 3-O-methylation of caffeal- and coniferal-aldehyde/alcohol precursors to $\mathrm{G}$ and S lignin [28,29]. In Brachypodium distachyon, COMT has high affinity for a variety of substrates including flavonoid compounds, with the greatest activity with caffeic acid and caffealdehyde [30]. Transgenic downregulation of COMT has been reported in eudicots including $M$. sativa [31], N. tabacum [32,33], and Populus sp. [18,34,35]. Reports of COMT-downregulated transgenic grasses are more limited, including P. virgatum [36], Z. mays [37], F. arundinacea [38] and Lolium perenne [39]. Perturbation of the COMT enzyme often results in the inhibition of $S$ lignin formation and consequently the accumulation of 5$\mathrm{OH}$ coniferyl alcohol that could not be synthesized into $\mathrm{S}$ lignin is instead converted into a $G$ lignin monomer, resulting in incorporation of a novel 5-hydroxyguaiacyl lignin unit into the lignin polymer [33,40]. Accordingly, COMT transgenics with altered lignin composition tend to be more digestible [26].

In the early 1920's, brown midrib (bmr) mutants were identified in $Z$. mays as displaying a brownish-red to tan pigmentation of the leaf midrib associated with reduced lignin content or altered lignin composition [41]. A similar discoloration was observed in lignified tissues in the stalk. Changes in development are also apparent, as exemplified by variation in flowering time [42]. While the bmr mutants tend to have improved digestibility, various unfavorable traits including decreased grain and stem yield, increased lodging, and increased disease susceptibility sometimes develop $[40,43,44]$. Mutants have been isolated in the $C_{4}$ grasses $Z$. mays, $S$. bicolor, and Pennisetum glaucum. Four bmr loci in Z. mays, bm1, $b m 2, b m 3$ and $b m 4$, represent spontaneous mutants that were first isolated almost a century ago; an additional locus, bm5, was identified later [40]. In S. bicolor, four brown midrib loci, $b m r 2, b m r 6, b m r 12$, and $b m r 19$, were isolated from mutagenized populations $[45,46]$. Three brown midrib mutants have been isolated in P. glaucum, although they have not been as well characterized [47]. In Z. mays and S. bicolor, the bmr phenotype is associated with orthologous loci that encompass $C A D$ and $C O M T$ genes. The $b m 1$ mutation affects expression of $Z m C A D 2$ and five alleles of the orthologous bmr6 have been characterized in S. bicolor [48-51]. The bm3 locus in Z. mays and bmr12 in S. bicolor correspond to orthologous COMT genes [52,53]. The bmr mutants have the potential to act as viable bioenergy crops, as the visual phenotype seems to be an effective marker for impaired lignin biosynthesis associated with improved digestibility. A more complete understanding of the genes responsible for the phenotype will help provide 
novel breeding strategies and expand the resources of conversion-efficient plants.

Grasses are a key source of grain and forage and have recently gained in importance as feedstocks for the biofuel industry. Large perennial bioenergy crops such as $P$. virgatum and Miscanthus sp. have a relatively long generation time, complex genomes, and tall stature that make these species difficult research subjects. In order to better understand grasses, the small annual grass, $B$. distachyon, was used here as a research model from which we can translate results to the improvement of crops for efficient biofuel production [54]. It has many attributes of a model system including a small diploid and sequenced genome, rapid generation time, short stature, and it is easily transformable [54]. In this study, we used artificial microRNAs to disrupt the function of candidate CAD or COMT genes, with the objective of characterizing their role in lignin biosynthesis in B. distachyon.

\section{Results}

Characterization and phylogenetic analysis of $B d C A D$ and BdCOMT gene families

Given their importance to monolignol synthesis in other plants, $C A D$ and $C O M T$ genes with a potential role in secondary cell wall lignification were identified and perturbed in order to evaluate their role in B. distachyon (Figure 1). Candidate genes were selected based on sequence homology to previously characterized genes. Seven putative BdCADs were identified by BLAST search of the $B$. distachyon genome with the Oryza sativa CAD protein family [55]. The BdCAD family consists of Bradi3g06480 (BdCAD1), Bradi3g17920 (BdCAD2), Bradi3g22980 (BdCAD3), Bradi4g29770 (BdCAD4), Bradi4g29780 (BdCAD5), Bradi5g04130 (BdCAD6), and Bradi5g21550 (BdCAD7); numbered sequentially as they appear in the genome. Multiple amino acid sequence alignment was performed with the seven candidate $B$. distachyon CAD family members along with S. bicolor (Sbbmr6), Saccharum officinarum (SoCAD), Z. mays (Zmbm1), P. virgatum (PviCAD), O. sativa (OsCAD2), F. arundinacea (FaCAD), and Triticum aestivum (TaCAD) CAD proteins. Alignment results indicate a high degree of similarity in conserved domains and binding residues characteristic of alcohol dehydrogenases, especially in BdCAD1 (Figure 2). All seven CAD family members in $B$. distachyon contain the $\mathrm{Zn}-1$ binding domain motif $\mathrm{GHE}(\mathrm{X})_{2} \mathrm{G}(\mathrm{X})_{5} \mathrm{G}(\mathrm{X})_{2} \mathrm{~V}$ and the conserved Zn-1 catalytic residues C47, H69, and C163. The sequence of the $\mathrm{Zn}-1$ binding motif is most highly conserved in BdCAD1, with 99.3\% homology to the motif in the other aforementioned grass species CAD proteins. A glycine-rich repeat $\mathrm{GXG}(\mathrm{X})_{2} \mathrm{G}$, involved in $\mathrm{NADP}(\mathrm{H})$ cosubstratebinding, is conserved amongst all $\mathrm{CAD}$ proteins. The consensus sequence $\mathrm{GD}(\mathrm{X})_{9,10} \mathrm{C}(\mathrm{X})_{2} \mathrm{C}(\mathrm{X})_{2} \mathrm{C}(\mathrm{X})_{7} \mathrm{C}$ for binding the $\mathrm{Zn}-2$ metal ion is preserved in the BdCADs. Additionally, twelve amino acids have been identified as substratebinding residues in the bona fide CADs of various plant species [56]. Of the seven CADs in B. distachyon, BdCAD1 contains ten of these twelve conserved residues, while the other family members are more variable at these positions. Interestingly, only BdCAD1 contains both active substratebinding residues, W119 and F298, which determine specificity for aromatic alcohols, and the conserved S212 residue that determines $\mathrm{NADP}(\mathrm{H})$ binding at that position, as seen in OsCAD2 in rice [55]. Pairwise sequence alignments with the BdCAD1 protein revealed high percent identity to $F$. arundinacea (89.7\%), T. aestivum (89.4\%), O. sativa (89.2\%), P. virgatum (87.5\%), Z. mays (88.3\%), S. officinarum (86.9\%), and S. bicolor (86.9\%). Based on amino acid sequence, it appears that BdCAD1 (Bradi3g06480) contains the conserved functional and structural features of a medium chain dehydrogenase/reductase specific to enzymes involved in lignin biosynthesis in secondary cell walls.

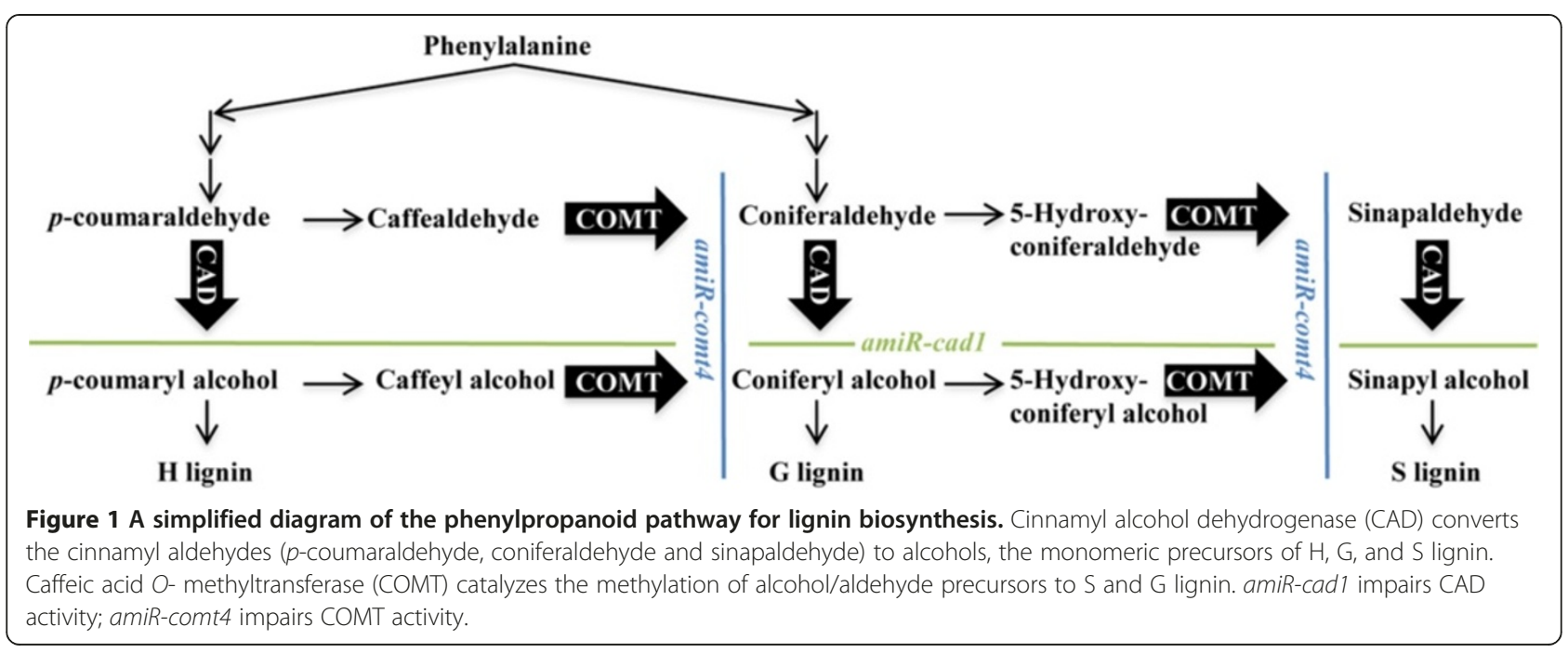




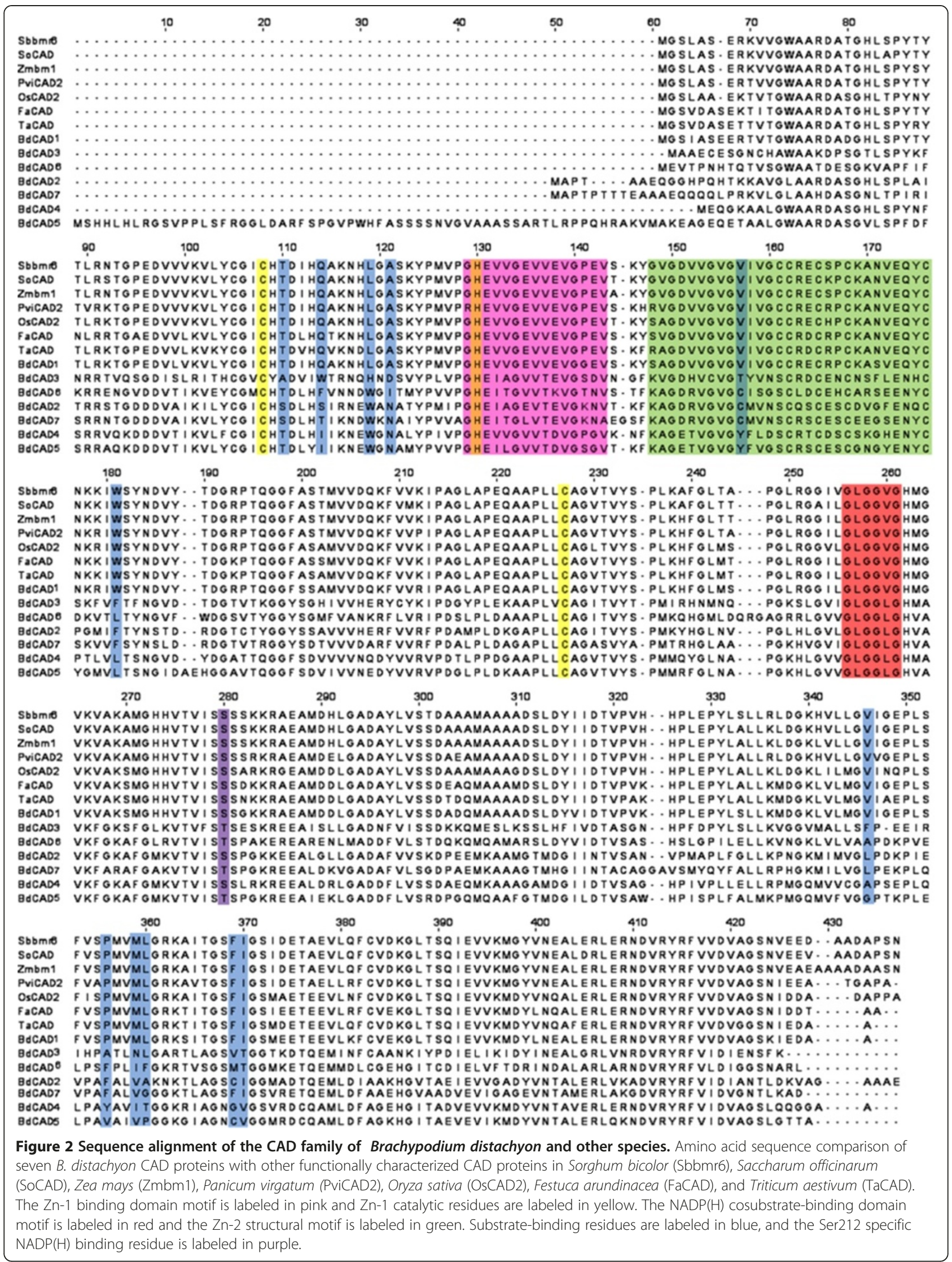


Four COMTs were identified in $B$. distachyon, Bradilg 14870 (BdCOMT1), Bradi2g02380 (BdCOMT2), Bradi2g 02390 (BdCOMT3), and Bradi3g16530 (BdCOMT4). Multiple amino acid sequence alignment was then performed with the four derived $B$. distachyon COMT family members and with known COMTs in T. aestivum (TaCM), F. arundinacea (FaCOMT), S. bicolor (Sbbmr12), S. offici narum (SoCOMT), Z. mays (Zmbm3), and P. virgatum (PviCOMT). Sequence comparison with the functionally characterized COMT proteins from various plants showed a high degree of similarity at the amino acid level (Figure 3). The S-adenosyl-L-methionine (SAM) binding domain, LVDVGGGxG, a signature of $O$-methyltransferases, is conserved in BdCOMT1, BdCOMT3, and BdCOMT4; however, one residue is inconsistent at position 193 in BdCOMT2, where isoleucine replaces valine in the sequence motif. Catalytic residues E310, E342, and R343 are conserved in all $B$. distachyon COMT family members and all other characterized COMT lignin proteins.
Interestingly, catalytic residue $\mathrm{H} 281$ found in $P$. virgatum, F. arundinacea, S. bicolor, and Z. mays, is conserved only in BdCOMT1 and BdCOMT4. Of the four BdCOMT family members, only BdCOMT4 has all substrate-binding and positioning residues M130, N131, L136, A162, H166, F176, M180, H183, I319, M320, N324 conserved in the known COMTs specific to the synthesis of secondary cell wall lignin. Pairwise sequence alignments with BdCOMT4 revealed high percent identity to $F$. arundinacea (89.2\%), $T$. aestivum (87.4\%), O. sativa (83.4\%), P. virgatum (83.4\%), S. officinarum (80.2\%), Z. mays (80.0\%), and S. bicolor (78.8\%). The prevalence of common signatures in the amino acid sequence supports the idea that BdCOMT4 is a COMT ortholog functioning as a SAM-dependent $O$ methyltransferase in $B$. disatchyon.

Evidence for the role of BdCAD1 and BdCOMT4 as functional lignin biosynthesis proteins was further enhanced by phylogenetic analysis. An unrooted neighbor-joining tree with 1000 bootstrap permutations was generated from the

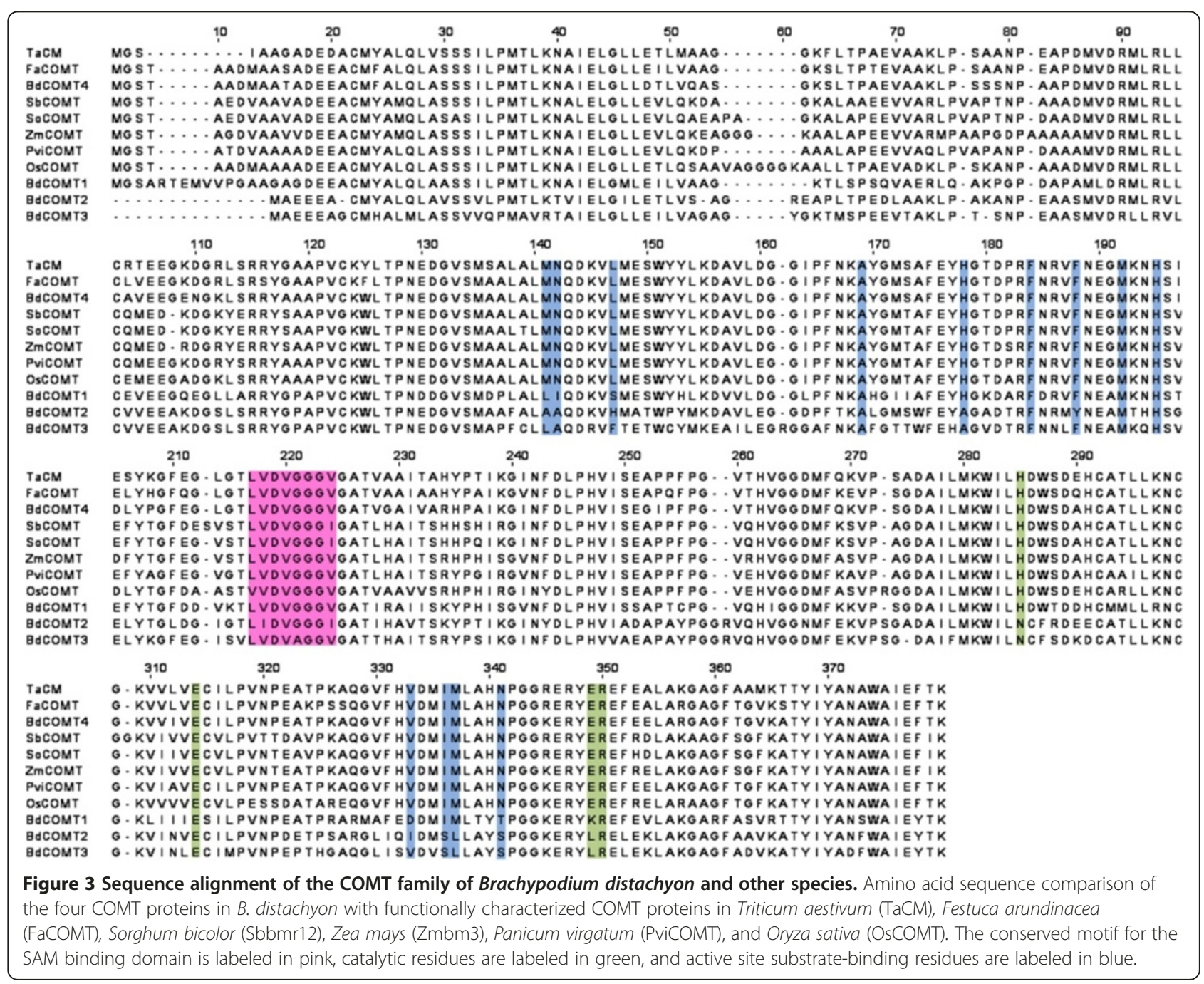


deduced multiple amino acid sequence alignments of the aforementioned CAD and COMT proteins. The phenogram established a single clade in which the characterized CAD proteins known to be involved in monolignol biosynthesis in monocots were clustered with one protein from our candidate $B$. distachyon family, BdCAD1 (Figure 4A). Within that clade, BdCAD1 clustered with $F$. arundinacea, $T$. aestivum and $O$. sativa proteins. A second, closely related group consisted of CADs in P. virgatum, Z. mays, S. bicolor, and $S$. officinarum. The remaining seven CAD family members in $B$. distachyon did not fall into any such existing clades. A similar trend was observed in the phylogenetic analysis of the COMT sequences isolated from the previously mentioned species. A common clade formed amongst the known COMT lignin proteins and included one COMT from the $B$. distachyon family, BdCOMT4 (Figure 4B). Within the clade, BdCOMT4 clustered with $F$. arundinacea and $T$. aestivum proteins, while a closely related group consisted of P. virgatum, Z. mays, S. bicolor, and $S$. officinarum proteins. In contrast, the other three BdCOMTs did not show a similar relationship to known
COMT enzymes. The relationships among the CAD and COMT sequences specifically portray $B d C A D 1$ and $B d C O M T 4$ as unique from any other candidates in the corresponding multi-gene families in B. distachyon.

\section{BdCAD1 and BdCOMT4 are highly expressed in developing stem}

Anatomical expression data were also considered in evaluating the multi-gene $B d C A D$ and $B d C O M T$ families for a role in lignification. We used microarray data to analyze gene expression of each member of the family in developing stems, roots, and leaves. Lignin biosynthesis genes are expected to be highly expressed in stems, where secondary cell walls are prevalent and lignification occurs, while remaining at relatively low levels in roots and especially leaves. Of the seven CAD genes identified in $B$. distachyon, $B d C A D 1$ expression was greatest in stem tissue, exhibiting ten-fold higher transcript level than any of the other seven $B d C A D$ genes (Figure 4C). Expression of BdCOMT4 was also greatest in the stem and was eighteen-fold greater than the expression of the

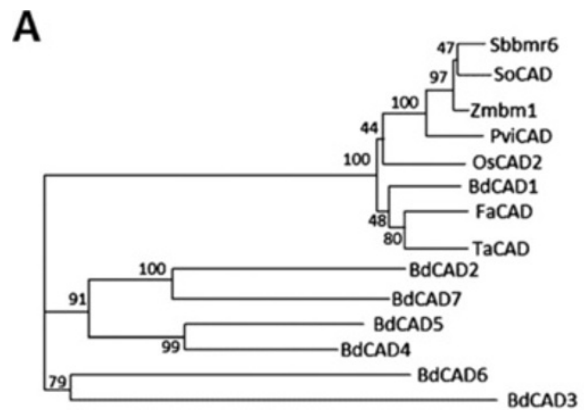

C

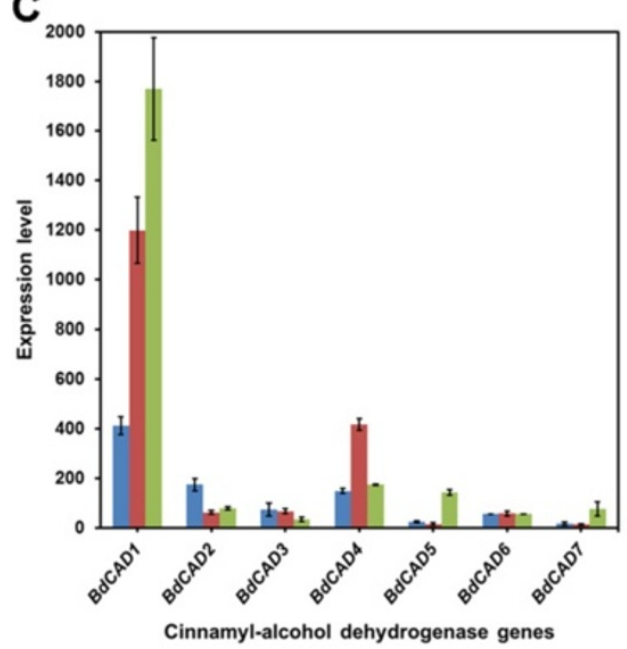

B

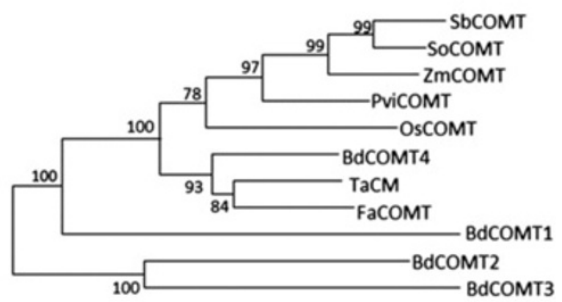

D

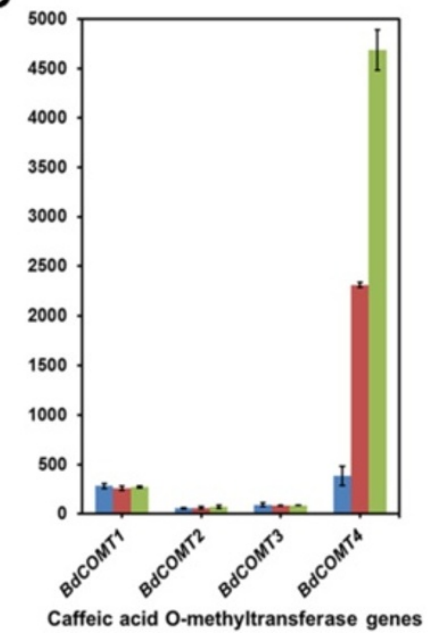

Figure 4 Phylogenetic analysis and expression patterns of CAD and COMT. (A,B) Unrooted phylogenetic tree of B. distachyon CAD and COMT families and characterized proteins from other grasses. A multiple amino acid sequence alignment was performed with ClustalW and the phenogram was constructed with MEGA neighbor-joining method with 1000 bootstrap permutations. (C,D) Anatomical gene expression in leaf (blue), root (red), and stem (green) of CAD and COMT families in B. distachyon. 
other three $B d C O M T$ genes (Figure 4D). As might be expected, both $B d C A D 1$ and $B d C O M T 4$ were expressed at a slightly lower level in roots, where lignin is also present, and at a significantly lower level in leaves, where there is not much lignin at all.

\section{$B d C A D 1$ and BdCOMT4 transgenic plants}

In order to functionally characterize $B d C A D 1$ and $B d C O M T 4$, reduction-of-function mutants were developed and assayed for changes in secondary cell wall composition. Highly specific artificial microRNA (amiRNA) constructs were designed to target and silence $B d C A D 1$ or BdCOMT4 (Figure 5A, B). The WMD Version 3 webbased tool was used to design amiRNA sequences for the transgenes. The $B d C A D 1$ transcript was targeted by a $21-$ mer sequence at nucleotides $950-970$ in the fourth exon (Figure 5A). The BdCOMT4 transcript was targeted by a 21-mer sequence at nucleotides $556-576$ in the second exon (Figure 5B). Two transformation events targeting BdCAD1 (amiR-cad1-1 and amiR-cad1-8) and three transformation events targeting BdCOMT4 (amiR-comt4-3, amiR-comt4-5, and amiR-comt4-7) were selected for further characterization in the $\mathrm{T}_{2}$ generation. Transgenic $B$. distachyon containing the empty binary vector pOL001 were used as control in all experiments. Anatomical expression data revealed that $B d C A D 1$ and $B d C O M T 4$ were highly expressed in stems; therefore, we analyzed the expression levels of the target genes in stems of the selected transgenic lines for both $B d C A D 1$ and $B d C O M T 4$ in order to confirm silencing. Quantitative real-time PCR of the $B d C A D 1$ or $B d C O M T 4$ transcript was performed to investigate the artificial microRNA induced suppression of $C A D$ or COMT. Relative expression of $B d C A D 1$ was significantly reduced in amiR-cad1-1 by $55 \%$ and amiR-cad1-8 by $31 \%$ compared to empty vector control (Figure $5 \mathrm{C}$ ). The expression level of BdCOMT4 was significantly decreased by 40,64 , and $34 \%$ in lines amiR-comt4-3, amiRcomt4-5, and amiR-comt4-7 respectively, compared to the empty vector control (Figure 5D).

The velocity of CAD in crude protein extracts was determined for aboveground tissue of empty vector control and $a m i R-c a d 1$ transgenic plants as the inflorescent first emerged from the flag leaf (Additional file 1: Figure S1). Sinapaldehyde was used as a substrate to evaluate total CAD activity that includes seven other putative CAD enzymes (Additional file 1: Figure S1). Although not statistically significant, total CAD activity was reduced by $6 \%$ in amiR-cad1-1 and $17 \%$ in amiR-cad1-8 plants relative to empty vector control.

\section{Effects of downregulation of BdCAD1 and BdCOMT4 on development}

Transgenic plants were assayed for changes in growth and development typical of lignin deficiency including time to flower, tiller number, and stem weight. Both $C A D$-downregulated events showed a significant delay
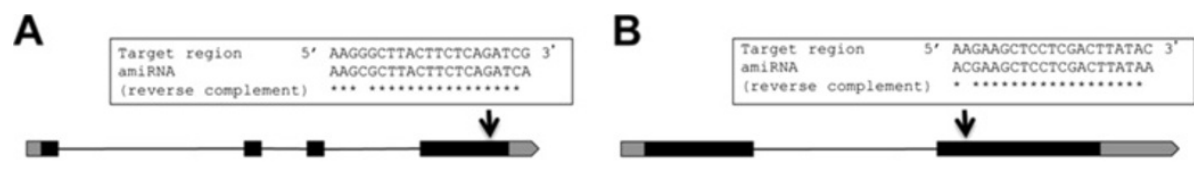

C

D
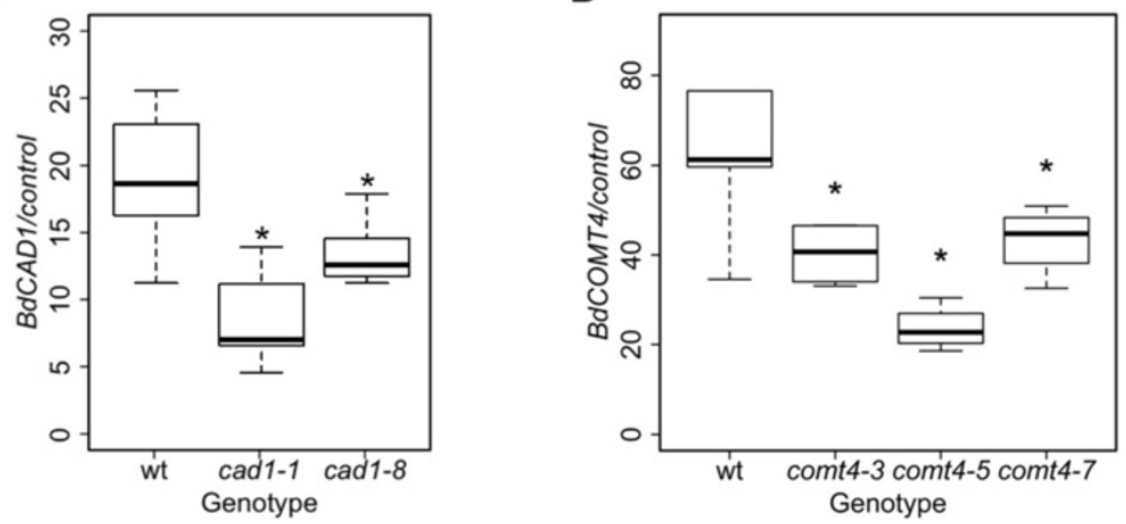

Figure 5 Design of artificial microRNA transgene constructs and relative expression of BdCAD1 and BdCOMT4 in transgenic plants. Artificial microRNA (amiRNA) constructs were designed to target and silence the (A) BdCAD1 and (B) BdCOMT4 transcripts. Exons are indicated by solid black boxes, untranslated regions by grey boxes, and intron by thin, black lines. The genes are drawn to scale. Arrows indicate the artificial microRNA target regions. RNA was prepared from stems of developmentally equivalent transgenic and empty vector control plants and subjected to quantitative real-time PCR to assay for target gene expression. Relative expression of (C) BdCAD1 and (D) BdCOMT4 with control housekeeping gene Bradi5g25870. The boxes show interquartile range, the whiskers show the outer quartile edge, and the black line represents the median of each distribution. Open circles represent outliers, when present. * Denotes significance at the $5 \%$ level. 
in inflorescence emergence, flowering on average ten days later than empty vector control plants (Figure 6A, B). On the other hand, amiR-comt4-3 and amiR-comt4-7 plants flowered significantly earlier than the empty vector control, but this difference was not observed in amiR-comt4-5 (Figure 6E, F). The amiR-cad1-1 and amiR-cad1-8 events showed a significant, near two-fold increase in tiller number (Figure $6 \mathrm{C}$ ). The tiller count among the amiR-comt4 mutants was significantly increased relative to the empty vector control for $a m i R$ comt4-3 and amiR-comt4-5 (Figure 6G). Total stem weight was measured at senescence following the removal of seeds and leaves. Events amiR-cad1-1 and amiR-cad1-8 showed a significant increase in stem biomass (Figure 6D), while all amiR-comt4 events were similar to the empty vector control (Figure $6 \mathrm{H}$ ).

\section{Transgenic plants have lignin-associated phenotypes}

The typical brown midrib phenotype was observed in all $C A D$-downregulated plants, but not in empty vector control or COMT-downregulated plants (Figure 7A-C). The leaf midrib appeared a brownish tan color in leaves of amiR-cad1-1 and amiR-cad1-8 plants and discoloration was consistently observed in successive leaves, while the control leaves remained green until senescence. Leaf midribs in amiR-comt4-3, amiR-comt4-5, and amiR-comt4-7 appeared similar in color to the control.

The effect of changes in BdCAD1 and BdCOMT4 transcript abundance on lignification was evaluated by histochemical analysis. Since $C A D$ is involved in the last step in the production of the precursors to $\mathrm{S}, \mathrm{G}$, and $\mathrm{H}$ lignin, we expected $B d C A D 1$-deficient plants to be altered in lignin (Figure 1). Lignin amount and localization was observed with Wiesner staining of hand-cut stem cross sections from the first internode of developmentally equivalent transgenic and empty vector control plants. The Wiesner reaction stains lignin in a concentration-indicative manner, whereby lignified tissue stains a dark red color and less lignified tissue an orange-yellow color. Empty vector control stem stained the dark red color for lignin (Figure 8A). There was a noticeable difference in staining in both amiRcad1 and amiR-comt4 stem sections relative to the control. The amiR-cad1 stems stained a visibly lighter yellow color in regions that appeared red in the control, most notably in the sclerenchyma fibers, epidermal cells, and vascular bundle sheath (Figure 8B). The amiR-comt4 stems stained an orange color relative to the red in the control, although this was mainly restricted to sclerenchyma fibers (Figure 8C).

Since COMT is important in the production of the sinapyl alcohol precursor for $\mathrm{S}$ lignin, we expected BdCOMT4-downregulated plants would exhibit a more drastic change, specifically in $\mathrm{S}$ lignin, more so than in total $\mathrm{G}$ and $\mathrm{H}$ lignin content (Figure 1). The Maule reagent was used to observe $\mathrm{S}$ lignin amount and localization in stems; the reagent stain $\mathrm{S}$ lignin a dark red-purple color. A shift to yellow-brown is indicative of a decrease in $\mathrm{S}$ lignin. Empty vector control stem sections treated with the Maule reagent stained a red-purple color (Figure 8D). Examination of the amiR-cad1 stems revealed a reduction in red staining and a slight shift to yellow-orange color, notably in the epidermal cells and sclerenchyma fibers (Figure 8E). There was a striking decrease in staining of the amiRcomt4 stem sections, in which the majority of tissue stained pale brown in color, with slight purple coloration seen in the outer regions of the pith (Figure 8F). The dramatic shift in color was reflective of a severe loss of S lignin in amiRcomt4 stems compared to the empty vector control.

\section{Effect of BdCAD1 or BdCOMT4downregulation on lignin composition}

To determine total lignin polymer content, plant material was subjected to hydrolysis by acetyl bromide $(\mathrm{AcBr})$ and fluorescent products, AcBr soluble lignin, were quantified by spectrometry. There was no significant difference in $\mathrm{AcBr}$ lignin content in $C A D$-downregulated plants as compared to the empty vector control (Figure 9A). On the other hand, AcBr lignin was significantly reduced by an average of $31.5 \%$ in amiR-comt4-3 and amiR-comt4-7 plants and $24 \%(P=0.08)$ in amiR-comt4-5 relative to the control.

Lignin composition was evaluated by thioacidolysis, which cleaves $\beta-\mathrm{O}-4$ ether bonds within the lignin polymer to reveal the monomer components. The recovered monomeric degradation products, namely $\mathrm{S}, \mathrm{G}$, and $\mathrm{H}$ units, were quantified by gas chromatography mass spectrometry. Empty vector control samples consisted of approximately 55\% S, 40\% G, and 5\% H lignin units. Monomer levels were altered in amiR-cad1 and amiR-comt4 plants (Table 1). Downregulation of $B d C A D 1$ was associated with a significant decrease in $S$ units and a slight yet not statistically significant increase in $\mathrm{G}$ units, resulting in a reduced $\mathrm{S} / \mathrm{G}$ ratio. Although $\mathrm{H}$ units were relatively scarce, they were increased in amiR-cad1 plants. The amiR-cad1-8 plants showed the most dramatic phenotype, in which the amount of S units and the S/G ratio were $16 \%$ and $22 \%$ lower than control. Although not statistically significant, the BdCOMT4-downregulated plants exhibited a $10 \%$ decrease in $\mathrm{S}$ units and a $17 \%$ reduction in $\mathrm{G}$ units, along with an increase in the $S / G$ ratio relative to empty vector control plants. No consistent difference in $\mathrm{H}$ lignin was observed in amiR-comt4 plants.

\section{Biological conversion efficiency in transgenic plants}

In order to evaluate the impact of lignin pathway modification on biofuel feedstock quality, we measured the potential of the transgenic plants to produce ethanol following inoculation with the cell-walldegrading, ethanogenic bacterium C. phytofermentans. 
A

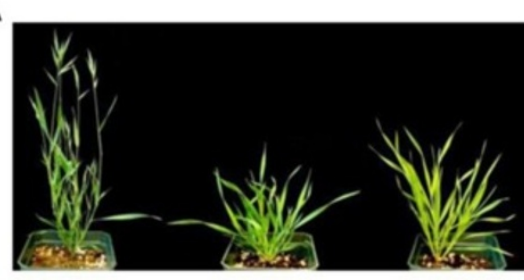

B

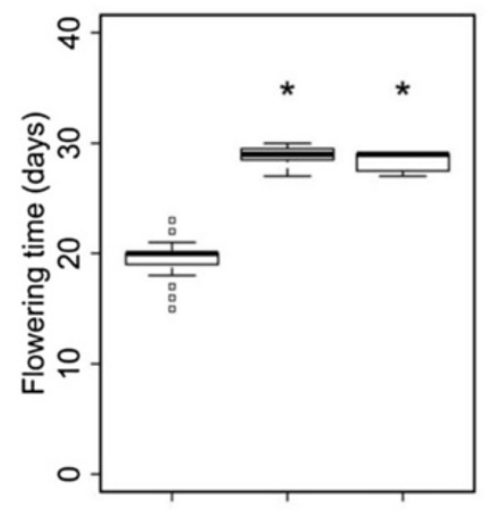

C

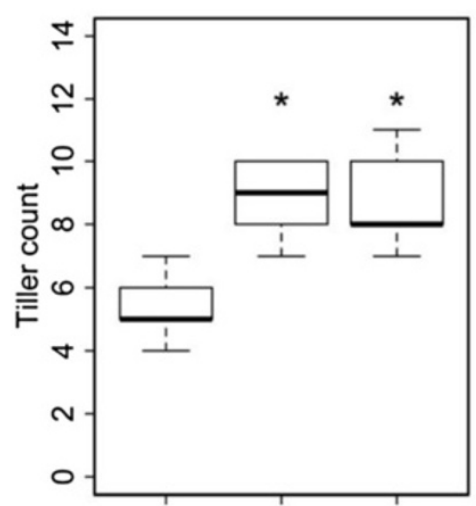

D

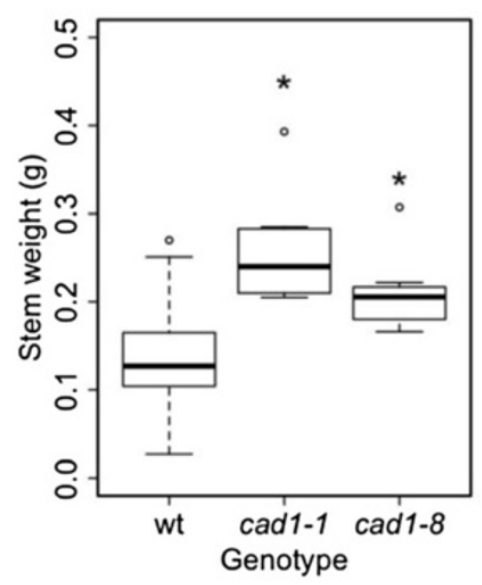

E

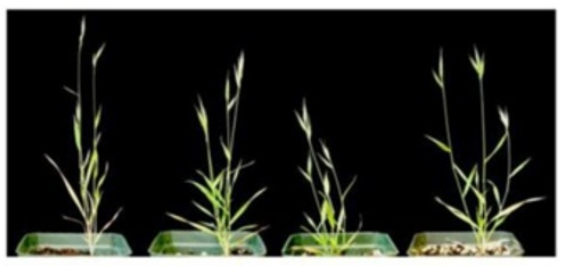

$\mathbf{F}$

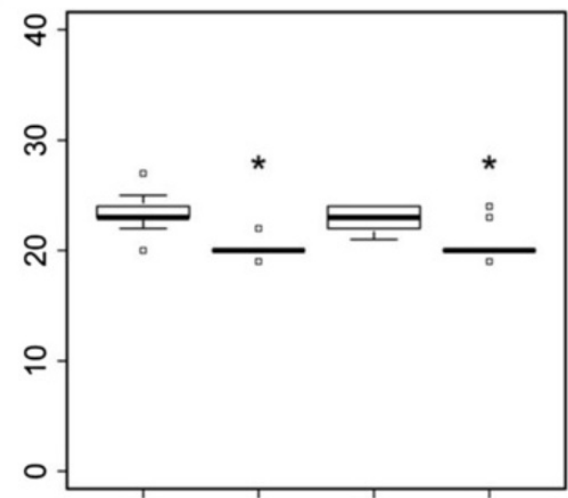

G

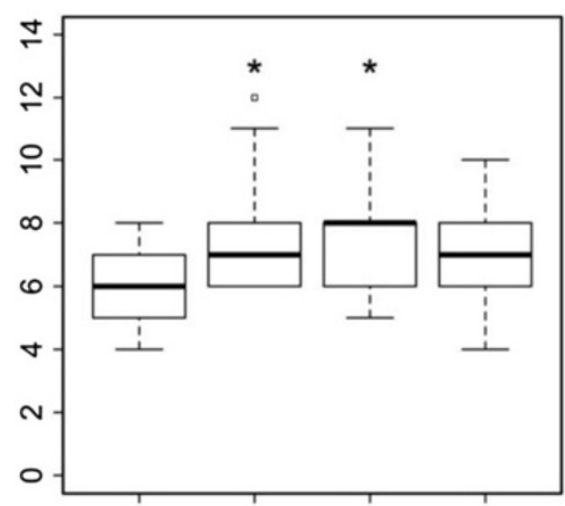

H

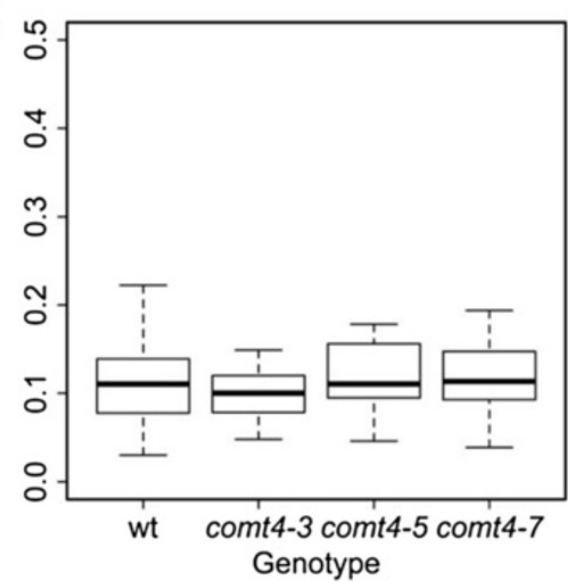

Figure 6 Transgenic growth and developmental phenotypes compared to empty vector control. (A-D) amiR-cad1, (E-H) amiR-comt4, and empty vector control. Box plots and significance are as described for Figure 5. 


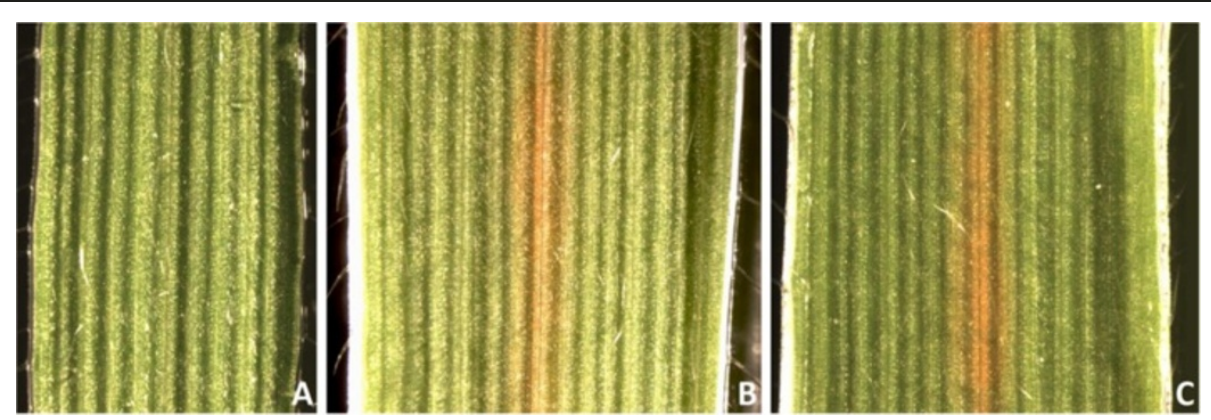

Figure 7 The amiR-cad1 transgene results in a brown midrib phenotype. For each line, a leaf was removed from the second node and imaged using darkfield microscopy. (A) empty vector control, (B) amiR-cad1-1, and (C) amiR-cad1-8. The brown pigmentation of the leaf midrib of transgenic CAD-downregulated plants was consistently observed in new leaves over time. The midrib of the empty vector control appeared green and no difference in pigmentation was observed. COMT-downregulated transgenics looked similar to control.
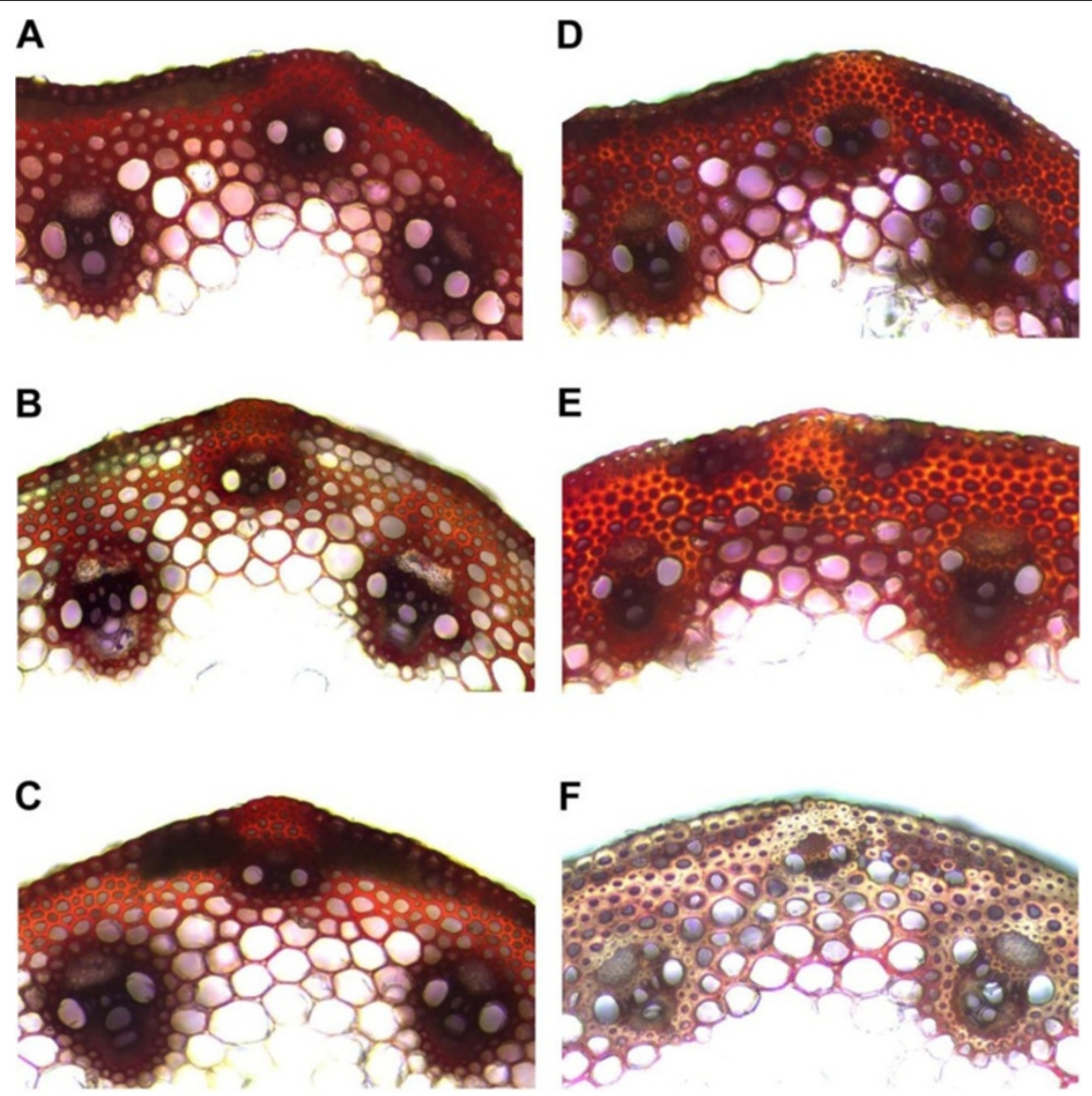

Figure 8 Histochemical analysis of lignin in stem. Cross sections of stems at the first internode of developmentally equivalent plants were dissected when the flag leaf was $4 \mathrm{~cm}$ below the spike. (A) to (C) Wiesner staining of empty vector control (A), amiR-cad1-1 (B), amiR-comt4-5 (C). Wiesner reagents stain lignified tissue in a concentration-indicative manner; heavily lignified tissue stains dark red, while areas with less lignin stain orange-yellow. (D) to (F) Maule reagent staining of empty vector control (D), amiR-cad1-1 (E), and amiR-comt4-5. The Maule reagent stains $\mathrm{S}$ lignin; a shift from red to brown-yellow is representative of a decrease in S lignin. 


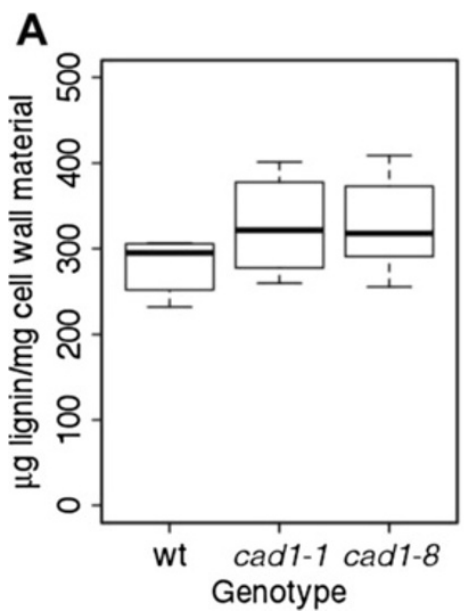

B

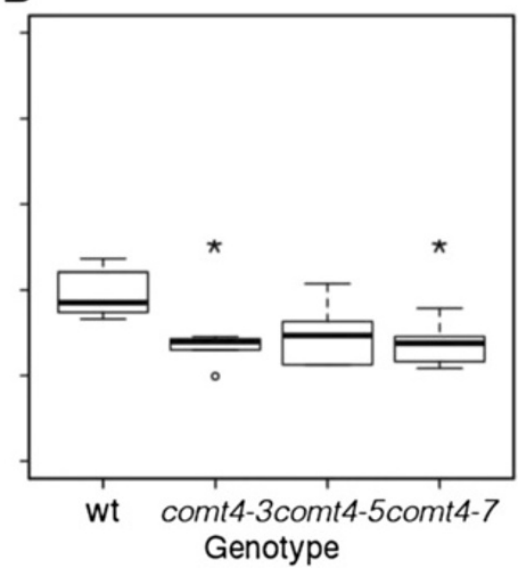

Figure 9 Acetyl bromide determination of lignin content. (A) amiR-cad1 and (B) amiR-comt4. Lignin content in senesced stem was measured in transgenics and empty vector control. Box plots and significance are as described for Figure 5.

A slight increase in average ethanol concentration was detected for both the amiR-cad1 and amiR-comt4 lines (Figure 10). Fermentation of the CAD-downregulated plants resulted in ethanol yields that were increased by $9 \%$ in amiR-cad1-1 and $17 \%(p=0.01)$ in amiR-cad1-8 lines relative to empty vector control plants. Digestion was slightly improved by COMT-downregulation, as ethanol yield was increased by $4 \%$ in amiR-comt4-3 ( $p=$ $0.76), 10 \%$ in amiR-comt4-5 ( $p=0.10)$, and $8 \%$ in $a m i R$ comt-4-7 lines $(p=0.24)$.

\section{Discussion}

In this study, we used a candidate gene approach to identify the $C A D$ and $C O M T$ genes involved in monolignol biosynthesis in B. distachyon. While well studied as key enzymes in the lignin pathway that influence forage quality, understanding of these enzymes is now of increased interest due to an apparently similar effect on biofuel feedstock quality [8]. To date, there have only been a few

Table 1 Lignin composition in CAD1- and COMT4downregulated transgenic plants

\begin{tabular}{|c|c|c|c|c|}
\hline Plant line $^{1}$ & $\mathrm{~S}(\mu \mathrm{mol} / \mathrm{g})^{2,3}$ & $\mathrm{G}(\mu \mathrm{mol} / \mathrm{g})^{2,3}$ & $\mathrm{H}(\mu \mathrm{mol} / \mathrm{g})^{2,3}$ & $\mathrm{~S} / \mathrm{G}^{2,3}$ \\
\hline Control 1 & $89.7 \pm 2.3$ & $69.5 \pm 1.4$ & $8.9 \pm 0.1$ & 1.29 \\
\hline amiR-cad1-1 & $87.7 \pm 1.8$ & $75.8 \pm 1.8$ & $10.0 \pm 0.1$ & 1.16 \\
\hline amiR-cad1-8 & $75.2 \pm 2.0$ & $75.0 \pm 1.7$ & $9.4 \pm 0.2$ & 1.00 \\
\hline Control 2 & $97.2 \pm 5.6$ & $65.7 \pm 3.6$ & $9.5 \pm 0.5$ & 1.48 \\
\hline amiR-comt4-3 & $86.6 \pm 3.8$ & $54.2 \pm 1.4$ & $8.9 \pm 0.2$ & 1.60 \\
\hline amiR-comt4-5 & $92.4 \pm 1.9$ & $60.0 \pm 0.9$ & $10.8 \pm 0.2$ & 1.54 \\
\hline miR-comt4-7 & $88.5 \pm 2.7$ & $55.8 \pm 1.3$ & $9.1 \pm 0.2$ & 1.58 \\
\hline
\end{tabular}

${ }^{1}$ Senesced stem tissue of amiRcad1 and amiRcomt4 were grown in different experiments with separate empty vector controls.

${ }^{2}$ Values are means $\pm S D(n=3)$.

${ }^{3}$ Syringyl (S), guaiacyl (G), p-hydroxphenyl (H) units. reports of $C A D$ or COMT downregulation in transgenic monocots [36-39]. These species, such as $F$. arundinacae and $L$. perenne have proven to be challenging research subjects. We report here the effectiveness of artificial microRNA silencing in a species considerably more amenable to research, $B$. distachyon, from which gained knowledge can be contributed towards the optimization of bioenergy grasses.

In monocots such as Z. mays, S. bicolor and O. sativa, CAD tends to exist as a multi-gene family with one CAD primarily involved in monolignol biosynthesis $[48,49,55]$. In contrast, in the eudicot $A$. thaliana, the last step of monolignol biosynthesis is controlled synergistically by two genes, AtCAD-C and AtCAD-D [57]. Based on amino acid sequence and gene expression pattern, we identified $B d C A D 1$ as a likely candidate for having a role in lignin biosynthesis. Albeit with significantly lower efficiency than BdCAD1, Bradi4g29770 can also use coniferyl aldehyde and coniferyl alcohol as substrates and may also have a role in monolignol biosynthesis [58]. Unlike the other BdCADs, BdCAD1 contains all sequence features characteristic of a zinc-dependent alcohol dehydrogenase and more specifically, appears to be a member of the medium-chain dehydrogenase/reductase superfamily. High similarity in sequence motifs and substrate binding position suggests that BdCAD1 shares the same function as the bona fide CADs [56]. Consistent with multi-gene CAD families in Z. mays, S. bicolor and $O$. sativa, one particular protein in $B$. distachyon shared a significantly higher degree of homology with other known CADs than any other family member $[48,49,55]$. Gene expression analysis revealed that $B d C A D 1$ was the most highly expressed member of the gene family and that transcript abundance was particularly high in stem and root, where secondary cell walls are prevalent. Lignin- 
A

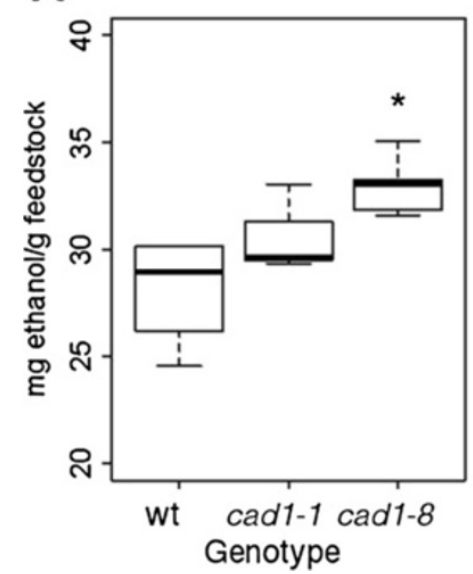

B

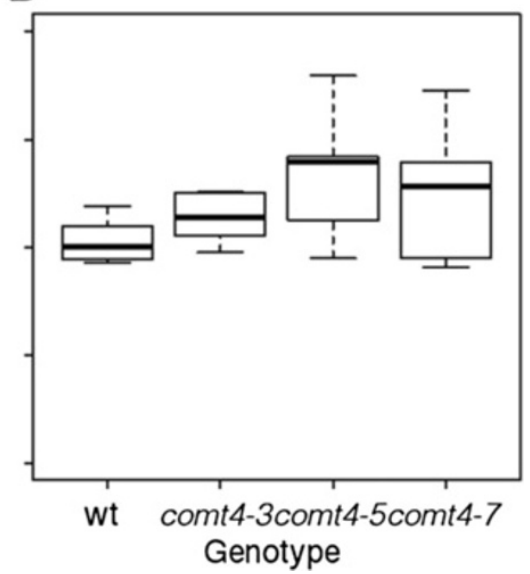

Figure 10 Biological conversion efficiency with the microbial system Clostridium phytofermentans. (A) amiR-cad1 (B) amiR-comt4. Ethanol yield from senesced stem was quantified in transgenics and empty vector control. Box plots and significance are as described for Figure 5.

associated $C A D$ expression was similarly high in stem and root tissues in P. virgatum, F. arundinacae, O. sativa, and S. bicolor $[22,38,55]$.

The downregulation of $B d C A D 1$ caused phenotypes characteristic of lignin deficiency without reducing plant biomass. The delay in flowering time of the amiR-cad1 plants is consistent with the phenotypes in five $S$. bicolor bmr mutants including CAD impaired bmr6 [42,59]. The variation in flowering time observed in lignin mutants from S. bicolor and B. distachyon reinforces the possibility of an evolutionarily conserved mechanism between cell wall biosynthesis and production of flowers [60]. Because lignin has a significant role in xylem function, it is possible that changes in lignin may alter development by perturbing water transport. However, this rationale seems unlikely considering that, while $a m i R$-cad 1 plants were developmentally delayed, mature transgenic plants were significantly larger than empty vector control plants (Figure 6D). An increase in aboveground stem biomass, even coupled with delayed flowering, is a favorable trait for a perennial energy crop, considering crop rotation will not be part of cultivation. While mutations in $C A D$ can sometimes lead to pleiotropic effects of dwarfing, lodging, and a decrease in grain and/or biomass yield, these effects are mostly background-dependent [40]. Further understanding of gene-by-gene interactions that result in these deleterious effects will increase the efficiency of cultivar development.

We present here the brown midrib leaf phenotype for the first time in a $C_{3}$ grass [40]. Genetic redundancy may explain why the phenotype has not been observed in mutant polyploid species such as $T$. aestivum and $F$. arundinacae; however, CAD mutants of diploid O. sativa do not exhibit a leaf brown midrib $[25,55,61,62]$. It has been suggested that the brown midrib phenotype may present itself differently in various species. In $O$. sativa, a mutation in GOLD HULL AND INTERNODE 2, which encodes a CAD enzyme, caused a red-brown pigment in the hull, internode, and basal leaf sheath while the leaf midrib did not show the same discoloration [63]. Similarly, recent research in $B$. distachyon indicated that CAD mutants displayed the red-brown pigmentation in various tissues including nodes and flowers, but not in the leaf midrib [64]. We did not observe color differences in tissues other than leaf midrib. In other species, including Populus sp. and N. tabacum, transverse stem cross-sections of transgenic $C A D$-downregulated plants exhibited unusually red xylem $[13,16,20]$. On the other hand, no visible mutant phenotype was observed in $C A D$-RNAi Z. mays plants [13]. Here, the BdCAD1downregulated plants phenotypically resembled $Z$. mays, $S$. bicolor, and P. glaucum leaf brown-midrib mutants. The brown-midrib phenotype may occur only when CAD activity is decreased beneath a certain threshold [65]. For example, in four lines of antisense-CAD transgenic tobacco with residual CAD activity ranging from $8-56 \%$, the extent of CAD downregulation was correlated with the presence and pattern of reddish-brown xylem [16]. We measured relatively small changes in CAD activity, but at a developmental stage that had not yet exhibited the brown-midrib phenotype. Nonetheless, the amiR-cad1-8 plants which were most reduced in CAD activity were significantly more digestible when the plant had completely senesced. It is possible at a subsequent developmental stage characterized by greater lignin biosynthesis that diminished CAD activity would be more evident.

The quality of lignin was altered in amiR-cad1 plants, as indicated by a significant decrease in $S$ units observed by thioacidolysis and in agreement with histochemical 
staining by the Maule reagent. Previous research in $C A D$ downregulated $N$. tabacum and $C A D$ mutant $B$. distachyon showed that the most dramatic change in lignin composition in plants was a severe decrease in S lignin $[16,64]$. Some $C A D$ gene knockouts produce functional lignin through increased incorporation of cinnamyl aldehyde subunits into the lignin polymer [43]. Previous reports for Z. mays, N. tabacum, and Populus sp. demonstrated an incorporation of aldehydes into the lignin polymer, in which increased coniferyl aldehyde caused an increase in intensity of the Wiesner stain [13,20]. On the contrary, the Wiesner stain in amiR-cad1 lines was less intense than control plants. A likely explanation is that the inhibition of $\mathrm{S}$ lignin synthesis still caused an accumulation of aldehydes, but specifically sinapyl aldehydes, which are not detected by Wiesner staining. This is consistent with decreased Wiesner staining and incorporation of 8-O-4coupled sinapyl aldehyde in $B$. distachyon CAD mutant plants [64].

Consistent with reports in N. tabacum, M. sativa, E. camaldulensis, Populus sp., F. arundinacae, and Z. mays, amiR-cad1 plants were unchanged in the amount of acetyl bromide soluble lignin polymer, but thioacidolysis indicated changes in lignin monomer composition [13,16-18, $20,21,24,38]$. The lignin in $C A D$ downregulated plants was generally more reactive. This has been illustrated by improved pulping properties in Populus sp., forage digestibility in N. tabacum and F. arundinacae, saccharification in $P$. virgatum and $B$. distachyon, and digestibility in $Z$. mays $[13,16-18,20,22,23,25,64]$. Along the same lines, the modified lignin in amiR-cad1-8 improved biological conversion efficiency by a statistically significant $17 \%$.

One protein among the four COMTs identified in $B$. distachyon, BdCOMT4 (Bradi3g16530), contained all of the signature features of a plant $O$-methyltransferase. Plant $O$-methyltransferases tend to have broad substrate specificity, and all nine substrate binding and positioning residues in BdCOMT4 are common to COMT proteins in other species. Similar to L. perenne, F. arundinacae, P. tremuloides, and M. sativa COMT genes [38,66-68], BdCOMT4 was the most highly expressed COMT in stem, root, and leaf tissues than any of the three other $B$. distachyon family members. Similar to observations made in P. tremuloides, BdCOMT4 expression was relatively low in leaves compared to stems [68]. Phylogeny, amino acid sequence, and the abundance of transcript in lignified tissues concurrently support that BdCOMT4 is an $\mathrm{O}$-methyltransferase involved in monolignol biosynthesis in B. distachyon.

The downregulation of COMT resulted in changes in various phenotypic traits. Mutants tended to flower earlier than the empty vector control, as seen for the lignin mutants bm1 in Z. mays and bmr7 in S. bicolor [42,59]. In general, the brown midrib phenotype is not common in
COMT-downregulated transgenic plants, with the only reports of a reddish-brown coloration of the leaf and internodes being in $Z$. mays $[37,69]$. Although the cause of discoloration in plants with impaired $C A D$ activity is often attributed to the incorporation of aldehydes into the lignin polymer, there is no obvious correlation between the phenotype and the activities of other enzymes of the monolignol biosynthesis pathway. Previous biochemical analysis has indicated that the brown coloration is not a result of accumulated carotenoids, anthocyanins, flavones, tannins, or flavonols, but could possibly be due to incorporation of other phenolic compounds into the lignin polymer [40]. Accumulation of novel 5-OH-G units has been observed in COMT-downregulated transgenic $M$. sativa and $Z$. mays, although a visual phenotype associated with this phenomenon has not been defined [33,37,69,70].

In our transgenic $B$. distachyon, the perturbation of the COMT enzyme had a deleterious effect on the total quantity of lignin produced in the plant. Similarly, downregulated COMT mutants in $Z$. mays, F. arundinacae, $L$. perenne, S. bicolor, and Saccharum spp. were also reduced in total lignin $[38,39,69,71]$. Staining with the Maule reagent revealed an obvious difference between control and amiR-comt4 transverse stem cross sections. We measured an increase in ethanol yield of up to $10 \%$ in amiR-comt4 lines, which is consistent with the characterization of COMT mutants in other species [33,37,38,69,71-73].

\section{Conclusion}

One of the more costly steps of producing liquid fuels from biomass on the biochemical platform is the pretreatment required to reduce biomass recalcitrance for the enzymatic and fermentation steps. As a result, there has been increasing effort to identify the factors behind biomass recalcitrance. In this study, modification of $C A D$ and $C O M T$ expression induced changes in cell wall composition that improved amenability to conversion. A significant $17 \%$ increase in ethanol yield from plant biomass, as observed here by $C A D$ downregulation, would increase industrial efficiency of processing such feedstock. Genetic modification of lignin biosynthesis may provide a means of improvement of biofuel crop conversion efficiency by reducing biomass pretreatment costs, thereby improving the bioethanol production process overall.

\section{Methods}

\section{Phylogenetic analysis}

Candidate CAD and COMT in B. distachyon were identified by amino acid homology with known proteins in other plant systems by BLAST search of the Phytozome v8.0 and NCBI databases [74,75]. Multiple amino acid sequences were aligned using ClustalW and analyzed with the associated editing program JalView 2.0 [76]. A 
neighbor-joining tree with bootstrap 1000 was constructed with MEGA [77]. Sequence data from this article can be found in the GenBank/EMBL databases under the following accession numbers: Sbbmr6 (BAF42789.1), Zmbm1 (ACG45271.1), PviCAD2 (ADO01602.1), OsCAD2 (NP_001046132.1), FaCAD (AAK97809.1), SoCAD (O82056.1), TaCAD (ADI59734.1), SbCOMT (AAO43609.1), Zmbm3 (NP_001106047.1), PviCOMT (ADX98508.1), TaCM (ABP63535.1).

\section{Microarray expression profiling}

Expression patterns of the multi-gene CAD and COMT families were observed using microarray expression profiling of leaf, root, and stem tissue of $B$. rachypodium distachyon. Plants were in a growth chamber at $20^{\circ} \mathrm{C}$ with $20 \mathrm{~h}$ light: $4 \mathrm{~h}$ dark cycles at a fluence rate of $220 \mu \mathrm{mol}$ of photons $\mathrm{m}^{-2} \mathrm{~s}^{-1}$ and relative humidity of 67-69. Additionally, for plate-grown plants, seeds were de-hulled and then imbibed in water for two hours with shaking. Then, seeds were treated with $70 \%$ ethanol for 20 seconds, rinsed with sterile water, then soaked in $1.3 \%$ sodium hypochlorite for 4 minutes at room temperature while shaking. Seeds were subsequently rinsed three times with sterile water and stored in the dark at $4^{\circ} \mathrm{C}$ for a minimum of 2 days in a sterile Petri dish with filter paper. Seedlings were grown for seven days on 0.5X Murashige and Skoog (MS) medium containing $0.7 \%$ bactoagar adjusted to a $\mathrm{pH}$ of 5.8 with $\mathrm{KOH}$.

Approximately 30 days following germination, total leaf and stem were collected as the inflorescence emerged from the flag leaf. Leaves were collected from the stems with a curved-tip probe. Nodes and internodes from the second leaf junction to the internode below the inflorescence were placed in a tube cooled with liquid nitrogen. Seven-day-old whole seedlings were flash frozen in liquid nitrogen and then the roots were snapped off into a sterile culture tube. The six time points were collected over the course of one day at ZT2, 6, 10, 14, 18, and 22. Three plants were dissected for each time point and in triplicate for each tissue type. Samples were stored in liquid nitrogen or at $-80^{\circ} \mathrm{C}$ until RNA extraction. Tissue was ground with mortars and pestles in liquid nitrogen. RNA was extracted using the Qiagen (Valencia, CA) Plant RNaeasy Kit according to the manufacturer's instructions. Labeled sense strand cDNA probes were synthesized using the Ambion WT expression kit.

Transcript abundance of three biological replicates of three-week-old leaves and stems, and seven day old roots was measured using the Affymetrix $B$. distachyon BradiAR1b520742 whole genome tiling array. The array contains $\sim 6.5 \mathrm{M}$ unique 25-mer oligonucleotide features, both the forward and reverse strand sequence. The complete genome sequence is tiled with an average of 30 bases between each array feature; 1.6 million features correspond to exons and introns and 4.9 million features between gene models. Version 1.0 genome annotation includes a total of 25,532 protein coding genes and 2,542 non-coding genes [74]. Approximately 95\% $(\sim 26,670)$ of the genes have at least five corresponding exon array features and from those a summary value was calculated for each gene model. The average number of array features corresponding to the CAD and COMT families is 38, ranging from 10 to 111. Probeset values were calculated using gcRMA. The Affymetrix BradiAR1b520742 GeneChip data (.CEL files) have been deposited at PLEXdb [Accession no: BD3].

\section{Generation of transgenic plants}

The WMD Version 3 web-based tool (http://wmd3. weigelworld.org) was used to design highly specific artificial microRNA (amiRNA) constructs to target the $B d C A D 1$ (Bradi3g06480) and BdCOMT4 (Bradi3g16 530) transcripts. This program selects a 21-mer sequence in the target gene from which an amiRNA can be produced. The gene aliases for $B d C A D 1$ and $B d C O M T 4$ were searched in the WMD-3 $B$. distachyon 1.0 genome database for the amiRNA sequence which would most likely hybridize to the target mRNA without affecting the rest of the genome. The native BdCAD1 transcript was targeted by the amiRNA sequence AA GCGCTTACTTCTCAGATCA, corresponding to part of the fourth exon, with hybridization energy of the target site in the target gene of $-38.50 \mathrm{kcal} / \mathrm{mol}$. The native BdCOMT4 transcript was targeted by the amiRNA sequence, ACGAAGCTCCTCGACTTATAA, correspon ding to the second exon, with hybridization energy of $-39.85 \mathrm{kcal} / \mathrm{mol}$.

Modified polymerase chain reactions were performed as described in the protocols section of the WMD3 website to engineer the amiRNA sequences into the endogenous $O$. sativa microRNA precursor osa-MIR528 in the PNW55 vector [78]. All PCRs were performed with Phusion High-Fidelity DNA Polymerase (New England Biolabs, Ipswitch, MA) according to the manufacturer's instructions. AmiRNA precursors were then cloned into the Gateway compatible vector pENTR/DTOPO (Invitrogen, Grand Island, NY). Following sequence confirmation, entry clones were recombined into the destination vector pOL001 using the LR Clonase II Plus enzyme (Invitrogen, Grand Island, NY). This vector confers hygromycin resistance with the HptII gene and will express the amiRNAs under the constitutive ubiquitin promoter $U B Q$ from $Z$. mays. Electroporation was used to transform the amiRNAs into Agrobacterium tumefaciens strain AGL1.

Transgenes were integrated into the $B$. distachyon accession Bd21-3 genome by Agrobacterium-mediated transformation of embryogenic calli following the protocol 
described by Vogel and Hill [79]. Regenerated plants from $B d C A D 1$ transformation events amiR-cad1-1 and amiRcad1-8 along with regenerated BdCOMT4 plants from transformation events amiR-comt4-3, amiR-comt4-5, and amiR-comt4-7 were selected for characterization in the $T_{2}$ generation. Control plants were obtained by transformation with the empty binary vector pOL001. Plants were grown in a growth chamber at $20^{\circ} \mathrm{C}$ with $20 \mathrm{~h}$ light: $4 \mathrm{~h}$ dark cycles at a fluence rate of $220 \mu \mathrm{mol}$ of photons $\mathrm{m}^{-2} \mathrm{~s}^{-1}$ and relative humidity of $67-69$.

Transgenic and empty vector control plants were genotyped by PCR of leaf genomic DNA. Leaf tissue was frozen in liquid nitrogen and pulverized with $6.35 \mathrm{~mm}$ stainless steel beads (BioSpec, Bartlesville, OK) in a Retsch Mixer Mill MM400. Pulverized tissue was treated with $600 \mu \mathrm{l}$ DNA Extraction Buffer $(100 \mathrm{mM} \mathrm{NaCl}, 50 \mathrm{mM}$ Tris, $25 \mathrm{mM}$ EDTA, 1\% SDS, $10 \mathrm{mM}$ 2-mercaptoethanol) at $65^{\circ} \mathrm{C}$ for 10 minutes. Samples were then placed on ice, mixed with $250 \mu \mathrm{l} 5 \mathrm{M}$ potassium acetate, and incubated for 20 minutes. The solution was centrifuged in a tabletop centrifuge at 12,000 rpm for 10 minutes. The supernatant was transferred to tubes containing $600 \mu \mathrm{l} 100 \%$ isopropanol, mixed, and centrifuged to pellet the DNA. The supernatant was discarded and the pellet rinsed with $300 \mu \mathrm{l}$ $70 \%$ ethanol. The pellet was resuspended in $225 \mu \mathrm{l} \mathrm{T}{ }_{10} \mathrm{E}_{5}$ (10 mM Tris, $5 \mathrm{mM}$ EDTA), mixed with $25 \mu \mathrm{l} 3 \mathrm{M}$ sodium acetate, $500 \mu \mathrm{l} 100 \%$ ethanol and centrifuged in a tabletop centrifuge at 10,000 rpm for 7 minutes. Supernatant was discarded and the pellet was rinsed with 70\% ethanol and centrifuged an additional 7 minutes. The pellet was allowed to air dry and was then resuspended in $30 \mu \mathrm{T}_{10} \mathrm{E}_{1}$ (10 mMTris, $1 \mathrm{mM}$ EDTA). All putative transgenic and empty vector control plants were tested for the presence of the HptII transgene by PCR of leaf genomic DNA with primer forward: 5' AGAATCTCGTGCTTT CAGCTTCGA 3' and primer reverse: 5' TCAAGACC AATGCGGAGCATATAC 3'. Only confirmed positive transformants were analyzed in subsequent experiments.

\section{Molecular characterization of transgenic plants}

Transgenic and empty vector control plants were subjected to quantitative real-time PCR to assay for $B d C A D 1$ and BdCOMT4 gene expression. Whole stem tissue was sampled as the inflorescence first emerged from the flag leaf, frozen in liquid nitrogen, and pulverized with $6.35 \mathrm{~mm}$ stainless steel beads (BioSpec, Bartlesville, OK) using Retsch Mixer Mill MM400. Total RNA was extracted from pulverized tissue using an RNeasy Plant Mini Kit (Qiagen, Valencia, CA) according to the manufacturer's instructions; RNA purification was analyzed with the NanoDrop1000 (ThermoScientific, Waltham, MA). RNA samples were reverse-transcribed into cDNA using the SuperScript III First-Strand Synthesis System (Invitrogen, Grand
Island, NY). Primers for gene-specific real-time PCR were selected using the QuantPrime design tool [80]. Reactions were completed using a QuantiFast SYBR Green PCR Kit (Qiagen, Valencia, CA) in an Eppendorf Mastercycler ep realplex2. To assay for $B d C A D 1$ expression, cDNA from amiR-CAD1 and empty-vector plants was amplified with $B d C A D 1$-specific primers (forward: 5'AGGATAGAATG GGCAGCATCGC 3'; reverse: 5' ATCTTCAGGGCCT GTCTTCCTGAG 3'). To assay for BdCOMT4 expression, cDNA from amiR-COMT4 and empty vector plant was amplified with $B d C O M T 4$-specific primers (forward: 5' TGGAGAGCTGGTACTACCTGAAG 3'; reverse: 5' CGACATCCCGTATGCCTTGTTG 3'). Expression values were normalized with the real-time PCR signal for the housekeeping gene Bradi5g25870 with its gene specific primers (forward: 5' - TCAGCAGGGTGCTAATTCAGT TC 3'; reverse: 5' CGACAGAGTTTAGCGGTCTTAGC $\left.3{ }^{\prime}\right)$. The selected housekeeping gene Bradi5g25870 exhibits moderate expression levels and extremely low variance across numerous $B$. distachyon array experiments. All qRT-PCR reactions were performed in triplicates.

\section{Enzymatic assays}

CAD activity was determined by generally following previously published procedures [50,81-83]. Approximately $150 \mathrm{mg}$ of frozen plant tissue that had been ground as previously described and stored at $-80^{\circ} \mathrm{C}$ was taken up in $700 \mu \mathrm{L}$ buffer (100 mMTris-Cl, pH 7.5, 5 $\mathrm{mM}$ DTT, 5\% ethylene glycol) and then sonicated to disrupt cell walls using a sonicator equipped with a micro-tip (Branson Digital Sonifier 450, Branson Ultrasonic Corp., Danbury CT). Sonicated extracts were centrifuged at $4^{\circ} \mathrm{C}$ for $10 \mathrm{~min}$. at $14,000 \mathrm{RPM}$ and the crude protein extract was placed into new $1.5 \mathrm{~mL}$ tubes and kept on ice. Each plant sample was extracted twice and enzyme activity was tested by monitoring absorbance changes on a microplate reader (BioTek Synergy $\mathrm{HT}$, BioTek Instruments, Winooski, VT) at $\mathrm{A}_{340}$. All reactions were carried out in a volume of $200 \mu \mathrm{L}$ and consisted of $100 \mathrm{mM}$ MES at pH 6.5, $200 \mu \mathrm{M}$ NADPH, 100 mMsinapyl aldehyde, and $10 \mu \mathrm{L}$ of the crude protein extract. Absorbance changes were monitored for three minutes after addition of crude protein extract. Enzyme velocities were determined by fitting a line using linear least squares to the absorbance data; the slope of the line was used in velocity determinations. Protein concentrations were determined using the Pierce $660 \mathrm{~nm}$ protein assay (Pierce Biotechnology, Rockford, IL) and served to normalize the calculated velocity for each extract.

\section{Histochemical staining of lignin}

Cross sections of stems were manually dissected from the first internode of developmentally equivalent transgenic 
and control plants. The Wiesner staining method [84] was used to visualize total lignin content and localization in the stem. Sections were stained with $1 \%$ phloroglucinol for 2 minutes followed by a wash in $50 \% \mathrm{HCl}$ and were mounted onto microscope slides for observation. The Maule reagent [85] was used to observe S lignin content and localization in stems. Sections were treated with $1 \%$ $\mathrm{KMnO}_{4}$ for 5 minutes and rinsed with water. Sections were then treated with $10 \% \mathrm{HCl}$ for 2 minutes, rinsed with water, and mounted on microscope slides in $1 \% \mathrm{NH}_{4} \mathrm{OH}$. Images were captured using a Nikon Eclipse E200MV R microscope with a 3 PixeLINK 3 MP camera.

\section{Lignin content and composition analysis}

Senesced stem material was dried thoroughly following wash steps with $70 \%$ ethanol at $65^{\circ} \mathrm{C}$ for 1 hour, and following ethanol removal was rinsed with acetic acid and allowed to air dry. Stem was pulvarized into powder with metal beads in a Retsch Mixer Mill MM400. Acetylbromide-soluble lignin was quantified using the procedure described by Foster et al. [86]. Triplicate samples of 1.5 mg powdered stem material were used for $\mathrm{AcBr}$ lignin analysis. Lignin composition was evaluated by thioacidolysis and $\mathrm{S}, \mathrm{G}$, and $\mathrm{H}$ unit quantification was conducted as described by Foster et al. [86].

\section{Digestibility analysis}

Biological conversion efficiency was measured using the microbial system developed for Clostridium phytofermentans, which converts plant biomass to ethanol, following the protocol as described by Lee et al. [72]. Triplicate $20 \mathrm{mg}$ samples, dried and prepared as described above, were incubated with C. phytofermentans in 96-well plates and supernatant ethanol concentration was measured with high-performance liquid chromatography (HPLC) with RI detection [87].

\section{Statistical analysis}

For each measurement, 4 to 17 independent plants were sampled. Analysis of variance and Dunnett's contrasts were performed in $\mathrm{R} v 2.15 .0$.

\section{Additional file}

Additional file 1: Figure S1. CAD enzyme activity in empty vector control and amiR-cad1 transgenic plants. Activity of CAD was measured in aboveground tissue using sinapaldehyde as a substrate. Box plots and significance are as described for Figure 5.

\section{Competing interests}

The authors declared that they have no competing interests.

\section{Authors' contributions}

GMT and SPH designed research; GMT, DAM, SJL, and AJS performed research; HDP, TCM, GS and SPH contributed new reagents/analytic tools;
SPH and HDP analyzed data; and GMT and SPH wrote the paper. All authors read and approved the final manuscript.

\section{Acknowledgements}

We thank Ludmila Tyler, Elsbeth Walker, and Ana Caicedo for helpful discussion and critical reading of this manuscript. We acknowledge Pubudu Handakumbura for expert assistance with tissue culture.

\section{Funding}

This research was supported by the Office of Science (BER) Department of Energy Grant DE-FG02-08ER64700DE to SPH and TCM.

\section{Author details}

'Biology Department, University of Massachusetts 221 Morrill Science Center III, Amherst, MA 01003, USA. ${ }^{2}$ Molecular and Cellular Biology Graduate Program, University of Massachusetts, Amherst, MA, USA. ${ }^{3}$ Plant Biology Graduate Program, University of Massachusetts, Amherst, MA, USA. ${ }^{4}$ USDA-ARS, Grain, Forage, and Bioenergy Research Unit, University of Nebraska-Lincoln, Lincoln, NE, USA. ${ }^{5}$ The Donald Danforth Plant Science Center, St. Louis, MO, USA.

Received: 20 May 2013 Accepted: 11 June 2013

Published: 31 July 2013

\section{References}

1. Somerville C: Biofuels. Curr Biology 2007, 17(4):R115-R119.

2. Archer D, Eby M, Brovkin V, Ridgwell A, Cao L, Mikolajewicz U, Caldeira K, Matsumoto K, Munhoven G, Montenegro A, et al: Atmospheric lifetime of fossil fuel carbon dioxide. Annu Rev Earth PI Sc 2009, 37:117-134.

3. Luthi $D$, Le Floch $M$, Bereiter B, Blunier T, Barnola J-M, Siegenthaler $U$, Raynaud D, Jouzel J, Fischer H, Kawamura K, et al: High-resolution carbon dioxide concentration record 650,000-800,000 years before present. Nature 2008, 453(7193):379-382.

4. Lynd L, Laser M, Brandsby D, Dale B, Davison B, Hamilton R, Himmel M, Keller M, McMillan J, Sheehan J, et al: How biotech can transform biofuels. Nat Biotechnol 2008, 26:169-172.

5. Carroll A, Somerville C: Cellulosic biofuels. Annu Rev Plant Biol 2009, 60(1):165-182

6. Keating JD, Panganiban C, Mansfield SD: Tolerance and adaptation of ethanologenic yeasts to lignocellulosic inhibitory compounds. Biotechnol Bioeng 2006, 93(6):1196-1206.

7. Chen F, Dixon R: Lignin modification improves fermentable sugar yields for biofuel production. Nat Biotechnol 2007, 25:759-761.

8. Vanholme R, Morreel K, Ralph J, Boerjan W: Lignin engineering. Curr Opin Plant Biol 2008, 11:278.

9. Bonawitz ND, Chapple $C$ : The genetics of lignin biosynthesis: connecting genotype to phenotype. Ann Rev Genet 2010, 44:337-363.

10. Vogel J: Unique aspects of the grass cell wall. Curr Opin Plant Biol 2008 11(3):301-307

11. Handakumbura PP, Hazen SP: Transcriptional regulation of grass secondary cell wall biosynthesis: playing catch-up with Arabidopsis thaliana. Front Plant Sci 2012, 3.

12. Rossmann MG, Moras D, Olsen KW: Chemical and biological evolution of a nucleotide-binding protein. Nature 1974, 250(5463):194-199.

13. Halpin C, Knight ME, Foxon GA, Campbell MM, Boudet AM, Boon JJ, Chabbert B, Tollier M-T, Schuch W: Manipulation of lignin quality by downregulation of Cinnamyl alcohol dehydrogenase. Plant J 1994, 6(3):339-350.

14. Bernard Vailhé MA, Besle JM, Maillot MP, Cornu A, Halpin C, Knight M: Effect of down-regulation of Cinnamyl alcohol dehydrogenase on cell wall composition and on degradability of tobacco stems. J Sci Food Agric 1998, 76(4):505-514.

15. O'Connell A, Holt K, Piquemal J, Grima-Pettenati J, Boudet A, Pollet B, Lapierre C, Petit-Conil M, Schuch W, Halpin C: Improved paper pulp from plants with suppressed Cinnamoyl-CoA reductase or Cinnamyl alcohol dehydrogenase. Transgenic Res 2002, 11(5):495-503.

16. Yahiaoui N, Marque C, Myton KE, Negrel J, Boudet AM: Impact of different levels of Cinnamyl alcohol dehydrogenase down-regulation on lignins of transgenic tobacco plants. Planta 1997, 204(1):8-15.

17. Baucher M, Bernard-Vailhe M, Chabbert B, Besle J, Opsomer C, Van Montagu M, Botterman J: Down-regulation of Cinnamyl alcohol dehydrogenase in 
transgenic alfalfa (Medicago sativa L.) and the effect on lignin composition and digestibility. Plant Mol Biol 1999, 39(3):437-447.

18. Lapierre C, Pollet B, Petit-Conil M, Toval G, Romero J, Pilate G, Leple J, Boerjan W, Ferret $V$, De Nadai $V$, et al: Structural alterations of lignins in transgenic poplars with depressed cinnamyl alcohol dehydrogenase or caffeic acid O-methyltransferase activity have an opposite impact on the efficiency of industrial kraft pulping. Plant Physiol 1999, 119(1):153-164.

19. Lapierre C, Pilate G, Pollet B, Mila I, Leple J-C, Jouanin L, Kim H, Ralph J: Signatures of cinnamyl alcohol dehydrogenase deficiency in poplar lignins. Phytochemistry 2004, 65(3):313-321.

20. Baucher M, Chabbert B, Pilate G, Van Doorsselaere J, Tollier MT, Petit-Conil M, Cornu D, Monties B, Van Montagu M, Inze D, et al: Red xylem and higher lignin extractability by down-regulating a Cinnamyl alcohol dehydrogenase in poplar. Plant Physiol 1996, 112(4):1479-1490.

21. Valério L, Carter D, Rodrigues JC, Tournier V, Gominho J, Marque C, Boudet A-M, Maunders M, Pereira $H$, Teulières C: Down regulation of Cinnamyl alcohol dehydrogenase, a lignification enzyme, in Eucalyptus camaldulensis. Mol Breed 2003, 12(2):157-167.

22. Fu C, Xiao X, Xi Y, Ge Y, Chen F, Bouton J, Dixon R, Wang Z-Y: Downregulation of Cinnamyl alcohol dehydrogenase (CAD) leads to improved saccharification efficiency in switchgrass. BioEnergy Res 2011, 4:153-164.

23. Saathoff AJ, Sarath G, Chow EK, Dien BS, Tobias CM: Downregulation of Cinnamyl-alcohol dehydrogenase in switchgrass by RNA silencing results in enhanced glucose release after cellulase treatment. PLoS One 2011, 6(1):e16416.

24. Fornale S, Capellades M, Encina A, Wang K, Irar S, Lapierre C, Ruel K, Joseleau J-P, Berenguer J, Puigdomenech P, et al: Altered lignin biosynthesis improves cellulosic bioethanol production in transgenic maize plants down-regulated for Cinnamyl alcohol dehydrogenase. Mol Plant 2011, 5(4):817-830.

25. Chen L, Auh CK, Dowling P, Bell J, Chen F, Hopkins A, Dixon RA, Wang ZY: Improved forage digestibility of tall fescue (Festuca arundinacea) by transgenic down-regulation of cinnamyl alcohol dehydrogenase. Plant Biotechnol J 2003, 1(6):437-449.

26. Li X, Weng J-K, Chapple C: Improvement of biomass through lignin modification. Plant J 2008, 54(4):569-581.

27. Joshi $C P$, Chiang VL: Conserved sequence motifs in plant S-adenosyl-Lmethionine-dependent methyltransferases. Plant Mol Biol 1998, 37(4):663-674

28. Whetten R, Sederoff R: Lignin biosynthesis. Plant Cell 1995, 7(7):1001-1013

29. Humphreys JM, Chapple C: Rewriting the lignin roadmap. Curr Opin Plant Biol 2002, 5(3):224-229.

30. Wu X, Wu J, Luo Y, Bragg J, Anderson O, Vogel J, Gu YQ: Phylogenetic, molecular, and biochemical characterization of caffeic acid omethyltransferase gene family in Brachypodium distachyon. Int J Plant Genomics 2013, 2013:12.

31. Guo D, Chen F, Wheeler J, Winder J, Selman S, Peterson M, Dixon RA: Improvement of in-rumen digestibility of alfalfa forage by genetic manipulation of lignin O-methyltransferases. Transgenic Res 2001, 10(5):457-464.

32. Ni W, Paiva NL, Dixon RA: Reduced lignin in transgenic plants containing a Caffeic acid O-methyltransferase antisense gene. Transgenic Res 1994, 3(2):120-126.

33. Guo D, Chen F, Inoue K, Blount JW, Dixon RA: Downregulation of Caffeic acid 3-O-methyltransferase and Caffeoyl CoA 3-O-methyltransferase in transgenic alfalfa: impacts on lignin structure and implications for the biosynthesis of $\mathrm{G}$ and S lignin. Plant Cell 2001, 13(1):73-88.

34. Van Doorsselaere J, Baucher M, Chognot E, Chabbert B, Tollier M-T, Petit Conil M, Leplé J-C, Pilate G, Cornu D, Monties B, et al: A novel lignin in poplar trees with a reduced Caffeic acid/5-hydroxyferulic acid $O$ methyltransferase activity. Plant J 1995, 8(6):855-864.

35. Jouanin L, Goujon T, de Nadai V, Martin M-T, Mila I, Vallet C, Pollet B, Yoshinaga A, Chabbert B, Petit-Conil $M$, et al: Lignification in transgenic poplars with extremely reduced Caffeic acid O-methyltransferase activity. Plant Physiol 2000, 123(4):1363-1374.

36. Fu C, Mielenz JR, Xiao X, Ge Y, Hamilton CY, Rodriguez M, Chen F, Foston M, Ragauskas A, Bouton J, et al: Genetic manipulation of lignin reduces recalcitrance and improves ethanol production from switchgrass. Proc Natl Acad Sci USA 2011, 108:3803-3803.
37. Pichon M, Deswartes C, Gerentes D, Guillaumie S, Lapierre C, Toppan A, Barrière $Y$, Goffner D: Variation in lignin and cell wall digestibility in Caffeic acid 0 -methyltransferase down-regulated maize half-sib progenies in field experiments. Mol Breed 2006, 18(3):253-261.

38. Chen L, Auh C-K, Dowling P, Bell J, Lehmann D, Wang Z-Y: Transgenic down-regulation of Caffeic acid $O$-methyltransferase (COMT) led to improved digestibility in tall fescue (Festuca arundinacea). Funct Plant Biol 2004, 31(3):235-245.

39. Tu Y, Rochfort S, Liu Z, Ran Y, Griffith M, Badenhorst P, Louie GV, Bowman ME, Smith KF, Noel JP, et al: Functional analyses of caffeic acid $O$ methyltransferase and cinnamoyl-CoA-reductase genes from perennial ryegrass (Lolium perenne). Plant Cell 2010, 22(10):3357-3373.

40. Sattler S, Funnell-Harris D, Pedersen J: Brown midrib mutations and their importance to the utilization of maize, sorghum, and pearl millet lignocellulosic tissues. Plant Sci 2010, 178:229-238.

41. Jorgensen JR: Brown midrib in maize and its linkage relationships. J Am Soc Agron 1931, 23:549-557.

42. Vermerris $W$, Mclntyre LM: Time to flowering in brown midrib mutants of maize: an alternative approach to the analysis of developmental traits. Heredity 1999, 83:171-178.

43. Barriere Y, Ralph J, Mechin V, Guillaumie S, Grabber JH: Genetic and molecular basis of grass cell wall biosynthesis and degradability. II. Lessons from brown-midrib mutants. C R Biol 2004, 327:847.

44. Pedersen JF, Vogel KP, Funnell DL: Impact of reduced lignin on plant fitness. Crop Sci 2005, 45(3):812-819.

45. Porter KS, Axtell JD, Lechtenberg VL, Colenbrander VF: Phenotype, fiber composition, and in vitro dry matter disappearance of chemically induced brown midrib (bmr) mutants of sorghum. Crop Sci 1978, 18(2):205-208.

46. Saballos A, Vermerris W, Rivera L, Ejeta G: Allelic association, chemical characterization and saccharification properties of brown midrib mutants of sorghum (Sorghum bicolor (L.) Moench). BioEnerg Res 2008, 1(3):193-204.

47. Cherney JH, Axtell JD, Hassen MM, Anliker KS: Forage quality characterization of a chemically induced brown-midrib mutant In pearl millet. Crop Sci 1988, 28(5):783-787.

48. Halpin C, Holt K, Chojecki J, Oliver D, Chabbert B, Monties B, Edwards K, Barakate A, Foxon GA: Brown-midrib maize (bm1) - a mutation affecting the cinnamyl alcohol dehydrogenase gene. Plant J 1998, 14:545-553.

49. Saballos A, Ejeta G, Sanchez E, Kang C, Vermerris W: A genomewide analysis of the cinnamyl alcohol dehydrogenase family in sorghum [Sorghum bicolor (L.) Moench] identifies SbCAD2 as the brown midrib6 gene. Genetics 2009, 181(2):783-795.

50. Sattler SE, Saathoff AJ, Haas EJ, Palmer NA, Funnell-Harris DL, Sarath G, Pedersen JF: A nonsense mutation in a Cinnamyl alcohol dehydrogenase gene Is responsible for the sorghum brownmidrib6 phenotype. Plant Physiol 2009, 150(2):584-595.

51. Gorthy S, Mayandi K, Faldu D, Dalal M: Molecular characterization of allelic variation in spontaneous brown midrib mutants of sorghum (Sorghum bicolor (L.) Moench). Mol Breed 2013, 31(4):795-803.

52. Vignols F, Rigau J, Torres M, Capellades M, Puigdomenech P: The brown midrib3 (bm3) mutation in maize occurs in the gene encoding caffeic acid O-methyltransferase. Plant Cell 1995, 7(4):407-416.

53. Bout $\mathrm{S}$, Vermerris W: A candidate-gene approach to clone the sorghum Brown midrib gene encoding Caffeic acid O-methyltransferase. MGG 2003, 269(2):205-214

54. Brkljacic J, Grotewold E, Scholl R, Mockler T, Garvin DF, Vain P, Brutnell T, Sibout R, Bevan M, Budak H, et al: Brachypodium as a model for the grasses: today and the future. Plant Physio/ 2011, 157(1):3-13.

55. Tobias C, Chow E: Structure of the Cinnamyl-alcohol dehydrogenase gene family in rice and promoter activity of a member associated with lignification. Planta 2005, 220(5):678-688.

56. Youn B, Camacho R, Moinuddin SGA, Lee C, Davin LB, Lewis NG, Kang C: Crystal structures and catalytic mechanism of the Arabidopsis cinnamyl alcohol dehydrogenases AtCAD5 and AtCAD4. Org Biomol Chem 2006, 4(9):1687-1697.

57. Sibout R, Eudes A, Mouille G, Pollet B, Lapierre C, Jouanin L, Seguin A: Cinnamyl alcohol dehydrogenase- $C$ and $-D$ are the primary genes involved in lignin biosynthesis in the floral stem of Arabidopsis. Plant Cell 2005, 17(7):2059-2076 
58. Bukh C, Nord-Larsen PH, Rasmussen SK: Phylogeny and structure of the cinnamyl alcohol dehydrogenase gene family in Brachypodium distachyon. J Exp Bot 2012, 63(17):6223-6236.

59. Vermerris W, Thompson KJ, McIntyre LM: The maize Brown midrib1 locus affects cell wall composition and plant development in a dosedependent manner. Heredity 2002, 88(6):450-457.

60. Vermerris W, Thompson K, McIntyre L, Axtell J: Evidence for an evolutionarily conserved interaction between cell wall biosynthesis and flowering in maize and sorghum. BMC Evol Biol 2002, 2(1):2.

61. Ma Q-H: The expression of caffeic acid 3-O-methyltransferase in two wheat genotypes differing in lodging resistance. J Exp Bot 2009, 60(9):2763-2771.

62. Hirano K, Aya K, Kondo M, Okuno A, Morinaka Y, Matsuoka M: OsCAD2 is the major $C A D$ gene responsible for monolignol biosynthesis in rice culm. Plant Cell Rep 2012, 31(1):91-101.

63. Zhang K, Qian Q, Huang Z, Wang Y, Li M, Hong L, Zeng D, Gu M, Chu C, Cheng Z: GOLD HULL AND INTERNODE2 encodes a primarily multifunctional cinnamyl-alcohol dehydrogenase in rice. Plant Physiol 2006, 140(3):972-983.

64. d'Yvoire MB, Bouchabke-Coussa O, Voorend W, Antelme S, Cézard L, Legée F, Lebris P, Legay S, Whitehead C, McQueen-Mason SJ, et al: Disrupting the cinnamyl alcohol dehydrogenase 1 gene (BdCAD1) leads to altered lignification and improved saccharification in Brachypodium distachyon. Plant J 2012, 73:496-508.

65. Anterola AM, Lewis NG: Trends in lignin modification: a comprehensive analysis of the effects of genetic manipulations/mutations on lignification and vascular integrity. Phytochemistry 2002, 61(3):221-294.

66. Inoue K, Sewalt VJH, Murray Ballance G, Ni W, Sturzer C, Dixon RA: Developmental expression and substrate specificities of slfalfa Caffeic acid 3-O-methyltransferase and Caffeoyl coenzyme A 3-Omethyltransferase in relation to lignification. Plant Physio/ 1998, 117(3):761-770.

67. MCAlister FM, Jenkins CLD, Watson JM: Sequence and expression of a stem-abundant caffeic acid O-methyltransferase cDNA from perennial ryegrass (Lolium perenne). Funct Plant Biol 1998, 25(2):225-235.

68. Bugos RC, Chiang VLC, Campbell WH: CDNA cloning, sequence analysis and seasonal expression of lignin-bispecific caffeic acid/5-hydroxyferulic acid O-methyltransferase of aspen. Plant Mol Biology 1991, 17(6):1203-1215.

69. Piquemal J, Chamayou S, Nadaud I, Beckert M, Barriere Y, Mila I, Lapierre C, Rigau J, Puigdomenech P, Jauneau A, et al: Down-regulation of Caffeic acid O-methyltransferase in maize revisited using a transgenic approach. Plant Physio/ 2002, 130(4):1675-1685.

70. Lapierre $C T$, Tollier MT, Monties B: A new type of constitutive unit in lignins from the corn bm3 mutant. CR Acad Sci 1988, 307:723-728.

71. Jung JH, Vermerris W, Gallo M, Fedenko JR, Erickson JE, Altpeter F: RNA interference suppression of lignin biosynthesis increases fermentable sugar yields for biofuel production from field-grown sugarcane. Plant Biotech J 2013, 11(6):709-16.

72. Lee SJ, Warnick TA, Pattathil S, Alvelo-Maurosa JG, Serapiglia MJ, McCormick $\mathrm{H}$, Brown V, Young NF, Schnell DJ, Smart LB, et al: Biological conversion assay using Clostridium phytofermentans to estimate plant feedstock quality. Biotechnol Biofuels 2012, 5(1):5.

73. Dien B, Sarath G, Pedersen J, Sattler S, Chen H, Funnell-Harris D, Nichols N, Cotta M: Improved sugar conversion and ethanol yield for forage sorghum (Sorghum bicolor L. Moench) lines with reduced lignin contents. BioEnerg Res 2009, 2(3):153-164.

74. Initiative TIB: Genome sequencing and analysis of the model grass Brachypodium distachyon. Nature 2010, 463(7282):763-768.

75. Altschul S, Madden T, Schaffer A, Zhang J, Zhang Z, Miller W, Lipman D: Gapped BLAST and PSI-BLAST: a new generation of protein database search programs. Nucleic Acids Res 1997, 25(17):3389-3402

76. Thompson JD, Higgins DG, Gibson TJ: CLUSTAL W: improving the sensitivity of progressive multiple sequence alignment through sequence weighting, position-specific gap penalties and weight matrix choice. Nucl Acids Res 1994, 22(22):4673-4680.

77. Tamura K, Peterson D, Peterson N, Stecher G, Nei M, Kumar S: MEGA5: molecular evolutionary genetics analysis using maximum likelihood, evolutionary distance, and maximum parsimony methods. Mol Biol Evol 2011, 28(10):2731-2739.
78. Warthmann $\mathrm{N}$, Chen $\mathrm{H}$, Ossowski S, Weigel D, Hervre P: Highly specific gene silencing by artificial miRNAs in rice. PLoS One 2008, 3(3):e1829.

79. Vogel J, Hill T: High-efficiency Agrobacterium-mediated transformation of Brachypodium distachyon inbred line Bd21-3. Plant Cell Rep 2008, 27(3):471-478

80. Arvidsson S, Kwasniewski M, Riano-Pachon D, Mueller-Roeber B: QuantPrime - a flexible tool for reliable high-throughput primer design for quantitative PCR. BMC Bioinforma 2008, 9(1):465.

81. Hawkins SW, Boudet AM: Purification and characterization of cinnamyl alcohol dehydrogenase isoforms from the periderm of Eucalyptus gunnii hook. Plant Physiol 1994, 104(1):75-84.

82. Mansell RL, Gross GG, Stöckigt J, Franke H, Zenk MH: Purification and properties of cinnamyl alcohol dehydrogenase from higher plants involved in lignin biosynthesis. Phytochemistry 1974, 13(11):2427-2435.

83. Saathoff A, Tobias C, Sattler S, Haas E, Twigg P, Sarath G: Switchgrass contains two cinnamyl alcohol dehydrogenases involved in lignin formation. BioEnergy Res 2011, 4(2):120-133.

84. Wiesner J: Note über das verhalten des phloroglucins und einiger verwandter körper zur verholzten zellmembran. Sitzungsberichte der kaiserlichen akademie der wissenschaften. Math Nat Classe 1978, 77:60-66.

85. Maule C: Das verhalten verholzter membranen gegen kaliumpermanganat, eine holzreaktion neuer art. Beiträge zur wissenschaftlichen Botanik 1901, 4:166-185.

86. Foster CE, Martin TM, Pauly M: Comprehensive compositional analysis of plant cell walls (lignocellulosic biomass) Part I: lignin. J Vis Exp 2010, 37:e1745.

87. Lee SJ, Warnick TA, Leschine SB, Hazen SP: A high-throughput biological conversion assay for determining lignocellulosic quality. Methods $\mathrm{Mol}$ Biol 2013, 918:341-349.

doi:10.1186/1472-6750-13-61

Cite this article as: Trabucco et al:: Functional characterization of cinnamyl alcohol dehydrogenase and caffeic acid O-methyltransferase in Brachypodium distachyon. BMC Biotechnology 2013 13:61.

\section{Submit your next manuscript to BioMed Central and take full advantage of:}

- Convenient online submission

- Thorough peer review

- No space constraints or color figure charges

- Immediate publication on acceptance

- Inclusion in PubMed, CAS, Scopus and Google Scholar

- Research which is freely available for redistribution
C) BioMed Central 